\title{
Altered patterns of gene expression distinguishing ascending aortic aneurysms from abdominal aortic aneurysms: Complementary DNA expression profiling in the molecular characterization of aortic disease
}

Tarek S. Absi, MD, ${ }^{a}$ Thoralf M. Sundt III, MD, ${ }^{a *}$ William S. Tung, MD, ${ }^{a}$ Marc Moon, MD, ${ }^{\text {a }}$ Jason K. Lee, MD,

Ralph R. Damiano, Jr, MD, and Robert W. Thompson, MD ${ }^{a, b, c}$

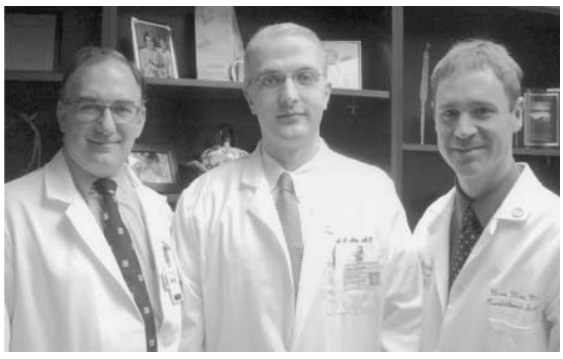

Thompson, Absi, Moon (left to right)

Objectives: The purpose of this study was to profile altered patterns of gene expression that characterize degenerative ascending thoracic aortic aneurysms and to compare these patterns with those observed for infrarenal abdominal aortic aneurysms.

Methods: Full-thickness aortic wall tissues were obtained during surgical repair of degenerative thoracic aortic aneurysms and infrarenal abdominal aortic aneurysms $(\mathrm{n}=4$ each), with normal thoracic and abdominal aortas from organ transplant donors used as control preparations. Radiolabeled complementary DNA was prepared for each specimen and hybridized to complementary DNA microarrays, and differential levels of

See related article on page 334 .

From the Departments of Surgery ${ }^{\mathrm{a}}$ (Sections of Cardiac and Vascular Surgery), Department of Radiology, ${ }^{\mathrm{b}}$ and Department of Cell Biology and Physiology, ${ }^{\mathrm{c}}$ Washington University School of Medicine, St Louis, Mo.

Supported by grants HL64332 and HL64333 from the National Heart, Lung, and Blood Institute.

Read at the Eighty-second Annual Meeting of The American Association for Thoracic Surgery, Washington, DC, May 5-8, 2002.

Received for publication June 6, 2002; revisions requested Aug 30, 2002; revisions received Sept 14, 2002; accepted for publication Oct 25, 2002.

Address for correspondence: Robert W. Thompson, MD, Section of Vascular Surgery, Washington University School of Medicine, 9901 Wohl Hospital, 4960 Children's Place, St Louis, MO 63110 (E-mail: thompsonr@msnotes.wustl.edu)

*Current address: Thoralf M. Sundt III, MD, Division of Cardiovascular Surgery, Mayo Clinic, 200 First St, Rochester, MN 55905 .

J Thorac Cardiovasc Surg 2003;126:344-57

Copyright () 2003 by The American Association for Thoracic Surgery

$0022-5223 / 2003 \$ 30.00+0$

doi:10.1016/S0022-5223(02)73576-9 gene expression between aneurysmal and normal aortic tissues at each site were assessed by parametric statistics.

Results: Of 1185 genes examined, 112 (9.5\%) were differentially expressed $(P<$ $.05)$ between thoracic aortic aneurysms and normal thoracic aorta, with 105 increased and 7 decreased. There were 104 genes (8.8\%) differentially expressed between infrarenal abdominal aortic aneurysms and normal abdominal aorta (65 increased and 39 decreased). Quantitative increases in expression for 97 genes were unique to thoracic aortic aneurysms, whereas increases for 61 genes were unique to infrarenal abdominal aortic aneurysms. Although 8 gene products were significantly altered in both thoracic and infrarenal abdominal aortic aneurysms, these changes were directionally concordant for only 4 (matrix metalloproteinase $9 /$ gelatinase B, v-yes-1 oncogene, mitogen-activated protein kinase 9, and intercellular adhesion molecule 1/CD54). Results for 9 genes were independently confirmed by quantitative reverse transcriptase-polymerase chain reaction.

Conclusions: Thoracic aortic aneurysms and infrarenal abdominal aortic aneurysms exhibit distinct patterns of gene expression relative to normal aorta from the same sites, with most alterations being unique to each disease. Degenerative aneurysms arising in different locations are thus characterized by a high degree of molecular heterogeneity, reflecting different pathophysiologic mechanisms.

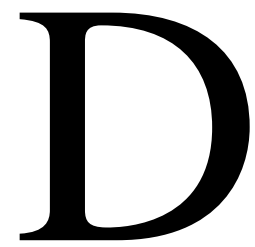

egenerative aortic aneurysms represent a relatively common condition responsible for considerable cardiovascular morbidity and mortality. Although aneurysms may arise at any site along the course of the aorta, they most frequently occur in the infrarenal abdominal aorta or the descending portion of the thoracic aorta. The ascending thoracic aorta is another common location for aortic aneurysms, which may develop in association with hypertension and spontaneous (type A) aortic dissection, congenital valvular abnormalities (eg, bicuspid 
aortic valves ${ }^{1-3}$ ), and inherited connective tissue disorders (eg, Ehlers-Danlos syndrome type IV ${ }^{4}$ Marfan syndrome, ${ }^{5}$ and other fibrillinopathies ${ }^{6,7}$ ). Genetic linkage studies have also revealed several new chromosomal loci associated with familial forms of thoracic aortic aneurysm and dissection, including a locus at 11q23.2-q24 and another at 5q13-14. ${ }^{8,9}$ Although candidate genes at each of these loci have been identified and examined, the genes responsible for aortic disease in these families have not yet been identified. Thus, despite significant progress during the past decade toward understanding the pathogenesis of aneurysmal disease, the specific factors causing aneurysmal degeneration in various locations remain unresolved.

Although it might be assumed that the pathophysiology of aortic aneurysms is homogeneous regardless of location, the histopathologic features of thoracic aortic aneurysms (TAAs) are quite different from those that characterize abdominal aortic aneurysms (AAAs). The microscopic findings in TAAs are most frequently described by the term "cystic medial necrosis," reflecting a noninflammatory loss of medial smooth muscle cells (SMCs), fragmentation of elastic fibers, and mucoid degeneration. ${ }^{10,11}$ In contrast, the histopathologic features of AAAs are dominated by severe intimal atherosclerosis, chronic transmural inflammation, and destructive remodeling of the elastic media. ${ }^{12,13} \mathrm{Al}-$ though it is clear that each of these pathologic patterns can be associated with aneurysm formation, it is uncertain how they are related to the underlying etiology and pathophysiology of aortic disease arising in these two different locations. ${ }^{14}$

Further evidence suggests that the cellular and molecular mechanisms underlying various forms of aneurysmal disease may also be different. Studies on human and experimental AAAs have focused on increased expression and tissue localization of elastin- and collagen-degrading enzymes, particularly matrix metalloproteinases (MMPs), cysteine proteases, and their respective inhibitors. ${ }^{15-18}$ Genes encoding a number of proinflammatory cytokines, chemotactic factors, and cell adhesion molecules have also been implicated in AAAs, ${ }^{19}$ and depletion of vascular SMCs may have an important influence the process of vascular remodeling that occurs during aneurysmal degeneration. ${ }^{20,21}$ Studies focusing on TAAs have indicated that cystic medial necrosis is also associated with elastin degradation and fragmentation, ${ }^{22,23} \mathrm{SMC}$ depletion and apoptosis, ${ }^{24}$ and increased expression of at least some MMPs. ${ }^{25,26}$. However, the absence of a significant inflammatory response implies alternative mechanisms of aneurysm formation in TAAs versus AAAs, perhaps related to the different embryologic origin of cells populating the ascending and infrarenal aorta, differing structural properties and propensities toward atherosclerotic degeneration, or the distinct hemodynamic conditions that distinguish these two areas. Despite ongoing investigations regarding the fundamental mechanisms responsible for aneurysmal degeneration, the spectrum of molecular alterations that may occur in aneurysms at different sites remains unknown.

The development of microchip- and membrane-based complementary DNA (cDNA) arrays has recently made it possible to examine simultaneous expression of thousands of gene products in the same experiment. ${ }^{27-31}$ Microarray techniques have been applied to diverse disease processes, including human atherosclerosis and AAAs, yielding valuable insights into the pathologic profiles of altered gene expression in these conditions. ${ }^{32-34}$ Given the potential discoveries that might arise from more comprehensive understanding of altered gene expression in different forms of aneurysmal disease, the purpose of this study was to establish a transcriptional profile of aortic wall gene expression that occurs in TAAs relative to normal ascending aorta (NTA). A second goal of this study was to compare altered patterns of gene expression between TAAs and AAAs to determine the similarities and differences that may exist between these two conditions.

\section{Methods}

\section{Aortic Tissues}

Full-thickness aortic wall specimens were obtained from 4 patients undergoing elective surgical repair of asymptomatic TAAs ( 2 men and 2 women, ages $49,78,82$, and 52 years, mean age $65.3 \pm 4.3$ years). The mean aneurysm size was $6.0 \pm 0.4 \mathrm{~cm}$ by computed tomography $(5.0,5.0,8.0$, and $6.0 \mathrm{~cm})$. None of these lesions were associated with aortic dissection, congenital aortic valve abnormalities, inherited connective tissue disorders, or familial forms of aneurysmal disease, and no patients had AAAs. For comparison, 4 full-thickness specimens of NTA were obtained from cadaveric organ transplant donors without visible evidence of atherosclerosis ( 2 men and 2 women, ages 25, 40, 59, and 38 years, mean age 40.5 \pm 3.5 years).

A second series of full-thickness aortic wall specimens was obtained from 4 patients undergoing elective repair of asymptomatic AAAs, including 2 men and 2 women (ages 84, 80, 76, and 57 years, mean age $74.3 \pm 6.0$ years). The mean aneurysm size was $5.7 \pm 0.3 \mathrm{~cm}$ by computed tomography $(5.5,5.1,6.3$, and $6.0 \mathrm{~cm})$. None of the patients had "inflammatory" AAAs or aneurysms elsewhere. For comparison, specimens of normal infrarenal abdominal aorta (NAA) without visible evidence of atherosclerosis were obtained from 4 cadaveric organ transplant donors (3 men and 1 woman, ages $43,18,14$, and 36 years, mean age $27.8 \pm 7.0$ years).

All tissue specimens were snap-frozen in liquid nitrogen immediately on procurement and stored at $-70^{\circ} \mathrm{C}$ before nucleic acid extraction. All tissues were obtained with approval by the Washington University School of Medicine human research subjects committee.

\section{Light Microscopy}

Representative aortic tissue samples corresponding to each of the four groups were fixed in $10 \%$ neutral buffered formalin and 
processed for routine embedding in paraffin. Sections $(5 \mu \mathrm{m})$ were stained with Verhoeff-van Geisen stain for elastin and viewed by light microscopy.

\section{RNA Samples}

Each aortic tissue sample $(\mathrm{n}=16)$ was pulverized under liquid nitrogen, and total RNA was isolated with Trizol reagent (Gibco BRL, Grand Island, NY) ${ }^{35,36}$ RNA samples were further extracted with phenol and chloroform to eliminate excess protein, and residual DNA contamination was eliminated with RQ1 ribonucleasefree deoxyribonuclease (Promega Corporation, Madison, Wis). In some cases the samples were enriched for messenger RNA by incubation with streptavidin-coated magnetic beads and biotinylated oligodeoxythymidine (Atlas Pure Total RNA Labeling System; Clontech, Palo Alto, Calif).

\section{Preparation of Radiolabeled cDNA and Membrane Hybridization}

Radiolabeled cDNA was prepared with reagents and protocols provided with the AtlasArray Human 1.2 I cDNA Expression Array kit from CLONTECH (CLONTECH Laboratories, Inc, Palo Alto, Calif), as previously described elsewhere. ${ }^{33}$ For each of the 16 samples, $5 \mu \mathrm{g}$ total RNA was incubated with a mixture of array-specific oligonucleotide primers and 400 units of Superscript II reverse transcriptase (Gibco) in the presence of deoxyadenosine triphosphate labeled with phosphorus 32 (Amersham Pharmacia Biotech, Piscataway, NJ). Labeled cDNA samples were purified by column chromatography to remove unincorporated isotope before use. Each cDNA sample was mixed into hybridization buffer (ExpressHyb; CLONTECH) and then incubated overnight at $68^{\circ} \mathrm{C}$ with a nylon membrane containing bound cDNA clones corresponding to 1185 known genes (AtlasArray Human 1.2 I; CLONTECH). Membranes were washed according to the manufacturer's protocol, exposed to a phosphor screen (Eastman Kodak Company, Rochester, NY), and subsequently scanned (Molecular Dynamics, Inc, Sunnyvale, Calif). Densitometry readings for each gene were obtained with AtlasImage 1.01a (CLONTECH) and adjusted for the background density adjacent to each immobilized target cDNA on the same membrane. ${ }^{33}$

\section{Data Analysis}

The relative signal intensity for each gene on a given membrane was calculated as a fraction of the total signal intensity for all genes on the same membrane. The entire data set of adjusted intensity levels was entered into a commercially available data analysis and display platform specifically designed for high-density genomic expression studies (GeneSpring 4.0.4; Silicon Genetics, Redwood, Calif). Data were thereafter accessible for both mathematic computations and a number of different color graphic analytic display options, including the construction of experimental gene trees (dendrograms), self-organizing maps, statistical comparisons, and hierarchic cluster analysis (for reviews of these techniques, see Eisen and colleagues ${ }^{29}$ and Lockhart and cowork$\mathrm{ers}^{31}$ and references contained therein).

For each gene represented on the microarray, the mean ratio of expression (or fold change) in aneurysmal tissue was calculated by comparison with the mean values obtained for normal aorta from the same location (TAAs vs NTA and AAAs vs NAA). The data set was then examined with a parametric comparisons test to identify genes exhibiting different levels of expression between aneurysms and normal aorta. ${ }^{29,31}$ The two lists of differentially expressed genes were then compared to identify similarities and differences in the patterns of altered gene expression between TAAs and AAAs. To examine the consistency of changes in gene expression within the specimens from each group, the upper limit of normal expression was determined as the mean plus 2 SD of values obtained for the 4 normal aorta specimens. For genes reported to be expressed at increased levels, the number of individual aneurysm specimens exhibiting expression above the upper limit of normal was determined and recorded as a percentage of the total $(n=4)$ for each group. A similar analysis was performed for genes reported to be expressed at decreased levels, by determining the percentage of aneurysm specimens in which expression was below the lower limit of normal (mean minus $2 \mathrm{SD}$ ).

\section{Reverse Transcription-Quantitative Polymerase Chain Reaction}

To independently confirm results obtained by cDNA microarray analysis, the relative expression patterns of 9 selected genes were also measured by reverse transcription-quantitative polymerase chain reaction (RT-qPCR) assays. Reverse transcription was performed with $1 \mu \mathrm{g}$ total RNA isolated from each aortic tissue sample $(n=16)$ along with a GeneAmp 2400 thermal cycler and reagents from PE Biosystems (5.5-mmol/L magnesium chloride, 0.5-mol/L deoxyribonucleoside triphosphates, $1.25-\mathrm{U} / \mu \mathrm{L}$ MultiScribe Reverse Transcriptase, and $2.5-\mu \mathrm{mol} / \mathrm{L}$ random hexamers; PE Biosystems, Foster City, Calif). The cDNA samples were used for real-time detection of PCR amplification with SYBR Green, a fluorescent DNA binding dye (GeneAmp 5700 Sequence Detection System; PE Biosystems), as previously described elsewhere. ${ }^{36}$ Primer pairs were selected with PrimerExpress version 1.6 software (PE Biosystems) to amplify the following gene products: MMP-9/gelatinase-B (GenBank J05070), interleukin (IL) 6 signal transducer gp130 (GenBank M57230), v-yes-1 Yamaguchi sarcoma virus-related oncogene (GenBank M16038), apolipoprotein E (GenBank M12529), IL-8 (GenBank Y00787), IL-1 $\beta$ (GenBank K02770), tumor necrosis factor (TNF) $\alpha$ (GenBank X01394), vascular cell adhesion molecule 1 (GenBank M30257), cathepsin D (GenBank M11233), and $\beta$-actin (GenBank X00351).

All real-time polymerase chain reactions $(50 \mu \mathrm{L})$ were performed in duplicate with $10 \mathrm{ng}$ cDNA and kit reagents, with initial incubations at $50^{\circ} \mathrm{C}$ ( 2 minutes $)$ and $95^{\circ} \mathrm{C}$ (10 minutes) for AmpErase and AmpliTaq Gold activation, respectively, followed by 40 cycles of polymerase chain reaction $\left(95^{\circ} \mathrm{C}\right.$ for 15 seconds alternating with $60^{\circ} \mathrm{C}$ for 1 minute). Direct detection of reaction products was monitored by measuring the increase in fluorescence caused by the binding of SYBR Green I to double-stranded DNA products, along with an internal reference standard (ROX). Fluorescence signals were analyzed with the GeneAmp 5700 Sequence Detection System software (SDS version 1.3; PE Biosystems) according to the manufacturer's recommendations. All quantitative results were normalized to the mean concentration of $\beta$-actin messenger RNA to account for variability in the quality of total RNA and the efficiency of reverse transcription between samples. For each gene, statistical differences in expression between TAAs 


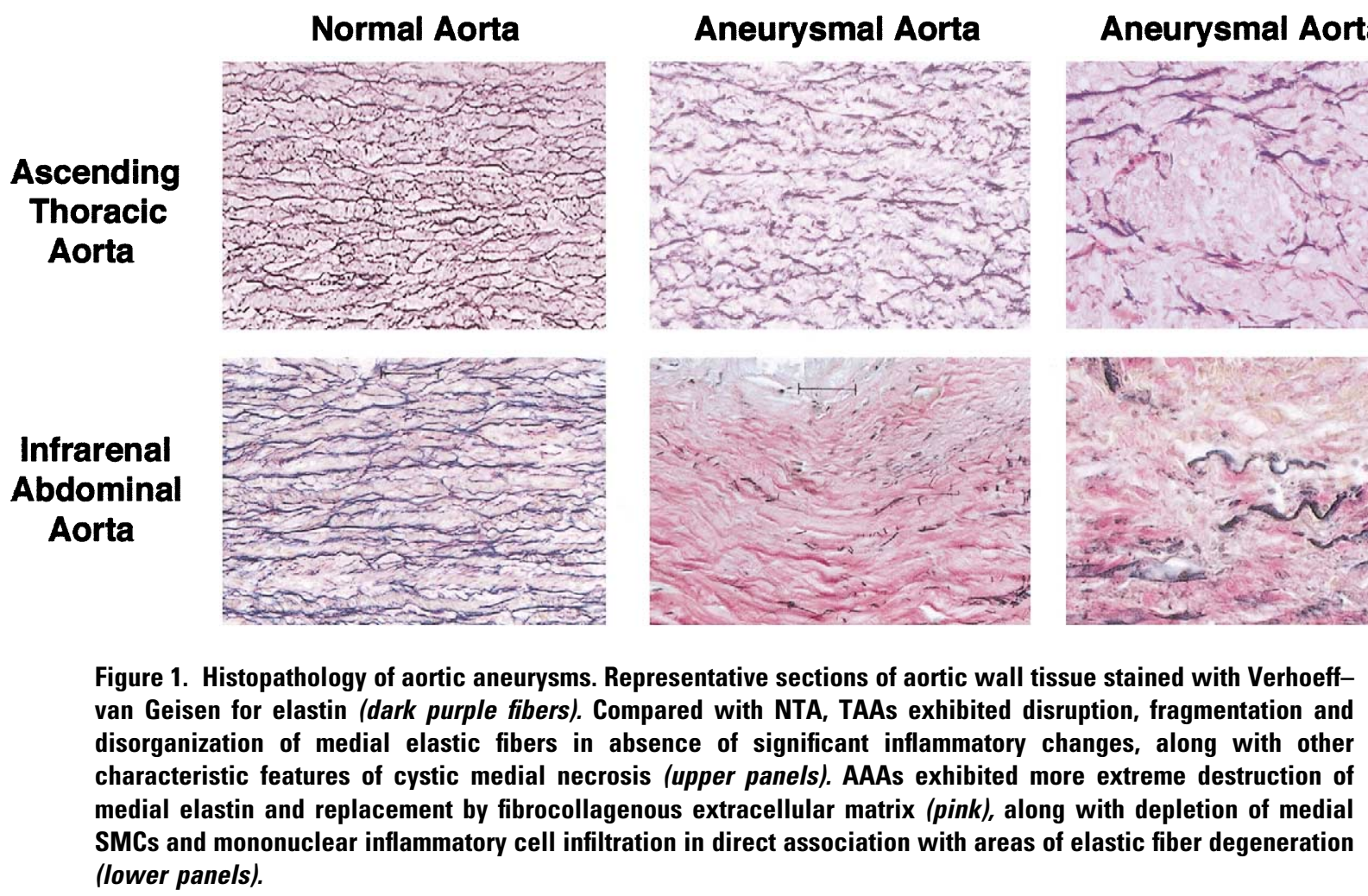

and NTA and between AAAs and NAA were analyzed by the paired Student $t$ test.

\section{Results}

Morphologic Appearance of Aneurysmal Tissues

Light microscopy of TAA tissues revealed disruption and disorganization of medial elastic fibers in the absence of significant inflammatory changes, along with areas of ground substance accumulation considered characteristic of cystic medial necrosis (Figure 1). In contrast, AAAs were characterized by more extreme destruction of medial elastic fibers with replacement by a fibrocollagenous extracellular matrix and depletion of medial SMCs. AAAs also exhibited infiltration of the media and adventitia by mononuclear inflammatory cells, often in direct association with degenerating elastic fibers (Figure 1).

\section{Microarray Data}

Representative hybridization blots for microarrays prepared from specimens of aneurysmal and normal thoracic aorta are shown in Figure 2. After phosphoimaging to quantify the relative expression level of each gene, data were corrected for the adjacent background intensity and normalized as a fraction of the total intensity observed on the entire blot. The complete data sets (adjusted intensities for each gene on each of 16 different arrays) were then entered into the GeneSpring program for further analysis. Figure 2, $B$, illus- trates a color display map depicting the relative levels of expression for all 1185 genes on the array in each sample of TAAs and NTA.

\section{Gene Expression Profiles of Aneurysmal Tissues}

One hundred twelve of 1185 genes represented on the microarray $(9.5 \%)$ were differentially expressed between TAAs and NTA $(P<.05)$, with 105 exhibiting a significant increase in expression and 7 exhibiting a significant decrease (Table 1). The magnitude of increased expression was at least 10-fold greater in TAAs than NTA for 17 of these transcripts, with the greatest increases observed for protein kinase C (PKC) $\zeta$ (>100-fold), uracil-DNA glycosidase (44-fold), lymphotoxin $\beta$ (41-fold), TNF- $\alpha$ (27-fold), and the TNF receptor superfamily member CD27 (18-fold). With regard to the consistency of these results, the alterations described were observed in at least 3 of the 4 individual TAA specimens for 95 of the 112 genes (85\%), including 92 of the 105 genes (88\%) exhibiting increased expression and 3 of the 7 genes (43\%) exhibiting decreased expression (Table 1).

One hundred four of 1185 genes $(8.8 \%)$ were differentially expressed between AAAs and NAA $(P<.05)$, with 65 exhibiting a significant increase in expression and 39 exhibiting a significant decrease (Table 2). Only 6 of these transcripts were increased greater than 10-fold between 
A
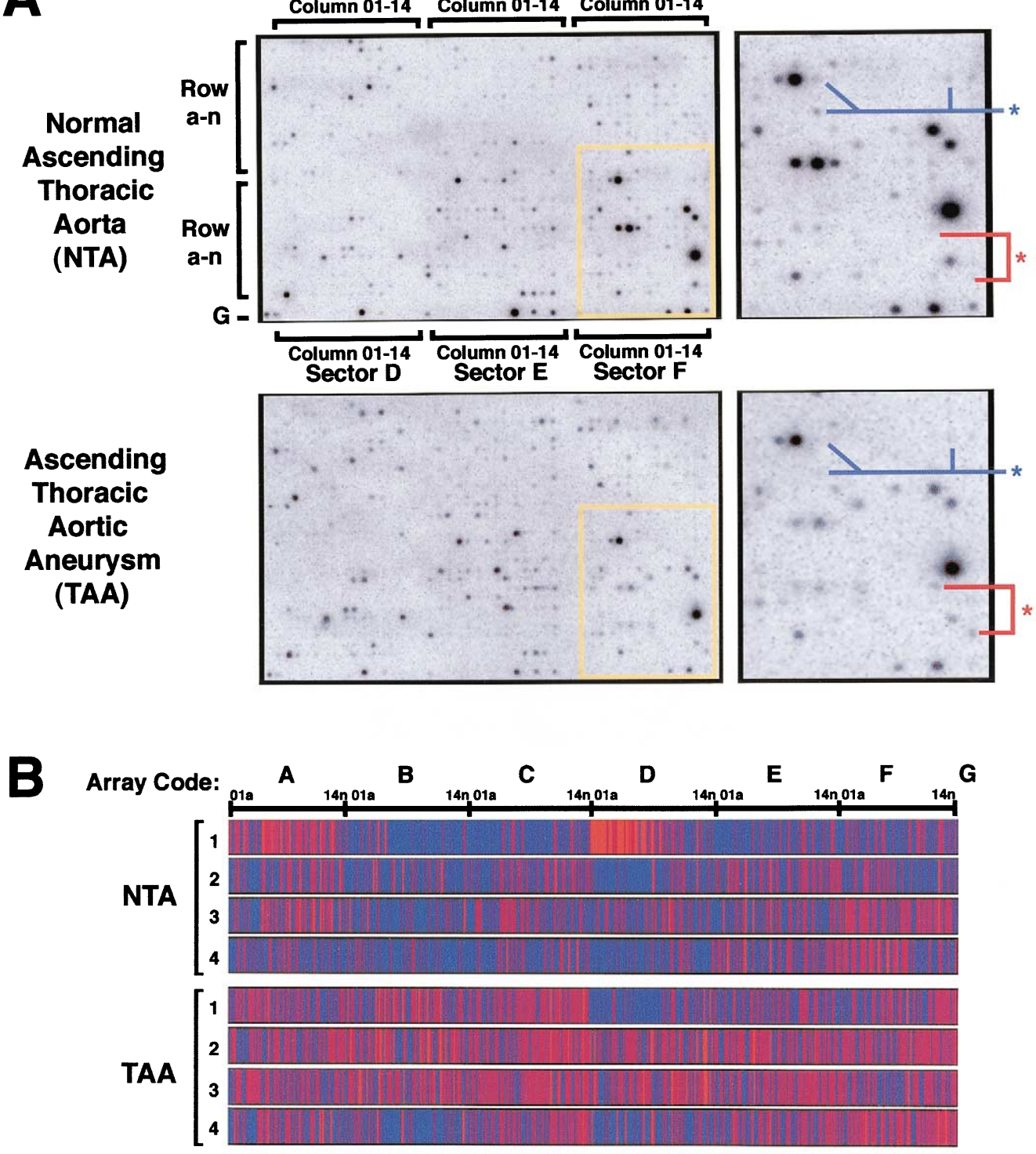

Relative Gene Expression

$\begin{array}{llllll}0.0 & 0.5 & 1.0 & 2.5 & 5.0 & 10\end{array}$

Figure 2. Microarray analysis of gene expression during aneurysm development. A, Representative autoradiographs for AtlasArray Human 1.2 I membranes (CLONTECH) blotted with phosphorus 32-labeled cDNA derived from NTA and TAA. Each blot contains bound cDNA clones from 1185 distinct gene products that can be identified by superimposing orientation grid provided by manufacturer, with each gene located by sectors $A$ through $F$, columns 01 through 14, and rows a through $n$ (sector $G$ denotes panel of 9 housekeeping genes; see manufacturer website for further details at http://atlasinfo.clontech.com). Differences in gene expression between blots can be visualized in higher resolution panels from the areas highlighted in yellow, as shown on far right (blue asterisks denote 3 genes exhibiting decreased expression in TAAs vs NTA and red asterisks denote 2 genes exhibiting increased expression). B, Color display illustrating relative levels of expression for all 1185 genes represented on AtlasArray Human 1.2 I microarray as generated by GeneSpring version 4.0.4 software (Silicon Genetics). Data shown reflect levels of relative gene expression (normalized relative intensities) for each individual gene in 4 specimens of NTA and 4 TAAs, where each gene is represented by single vertical band oriented according to array code shown above. Color bar (below) indicates spectrum of normalized relative intensities shown on color display, ranging from blue (low-level expression) to purple (mean expression) to red (high-level expression). 
TABLE 1. One hundred twelve genes exhibiting altered expression in TAAs

\begin{tabular}{|c|c|c|c|c|c|c|c|}
\hline Array code & $\begin{array}{c}\text { GenBank } \\
\text { reference }\end{array}$ & Gene or protein name & NTA & TAA & $\mathrm{A} / \mathrm{N}$ ratio & $P$ value & $\begin{array}{c}\text { Conservation } \\
(\%)\end{array}$ \\
\hline B09i & Z15108 & PKC $-\zeta$ & $0 \pm 0$ & $163 \pm 66$ & $>100$ & .048 & 100 \\
\hline $\mathrm{C} 14 \mathrm{n}$ & X15653 & Uracil-DNA glycosylase & $3 \pm 3$ & $131 \pm 41$ & 43.59 & .020 & 100 \\
\hline C10f & L11015 & Lymphotoxin $\beta$ & $10 \pm 10$ & $396 \pm 129$ & 41.05 & .024 & 100 \\
\hline $\mathrm{COBf}$ & X01394 & TNF- $\alpha$ & $23 \pm 9$ & $619 \pm 240$ & 26.63 & .047 & 100 \\
\hline $\mathrm{CO3g}$ & M63928 & CD27 (TNF receptor superfamily) & $106 \pm 38$ & $1927 \pm 638$ & 18.13 & .029 & 100 \\
\hline B10i & L07032 & PKC- $\theta$ & $6 \pm 6$ & $81 \pm 3$ & 14.05 & $<.001$ & 100 \\
\hline D13b & U31215 & Glutamate receptor metabotropic 1 & $5 \pm 5$ & $63 \pm 22$ & 13.72 & .039 & 75 \\
\hline $\mathrm{B} 13 \mathrm{c}$ & M12154 & Antigen p97 (melanotransferrin) & $9 \pm 9$ & $112 \pm 34$ & 12.43 & .026 & 75 \\
\hline B08j & M61906 & PI-3-kinase, regulatory subunit (p85 $\alpha$ ) & $9 \pm 9$ & $101 \pm 31$ & 11.64 & .029 & 75 \\
\hline B13k & M31158 & $\begin{array}{l}\text { Cyclic adenosine monophospate-dependent } \\
\text { protein kinase, type } \| \beta\end{array}$ & $11 \pm 8$ & $130 \pm 45$ & 11.54 & .041 & 75 \\
\hline B11c & M12530 & Transferrin & $10 \pm 6$ & $117 \pm 39$ & 11.26 & .035 & 100 \\
\hline A14e & M21574 & Platelet-derived growth factor receptor $\alpha$ & $113 \pm 77$ & $1246 \pm 419$ & 11.04 & .038 & 75 \\
\hline C14c & M97934 & STAT2 & $30 \pm 9$ & $333 \pm 47$ & 10.95 & .001 & 100 \\
\hline B03n & M28213 & $R A B 2$ (ras oncogene family) & $261 \pm 98$ & $2813 \pm 822$ & 10.80 & .022 & 100 \\
\hline B14l & X14034 & Phospholipase $\mathrm{C} \gamma 2$ & $24 \pm 16$ & $258 \pm 75$ & 10.60 & .023 & 100 \\
\hline D09i & Y00264 & Amyloid $\beta$ (A4) precursor protein & $976 \pm 110$ & $10,047 \pm 3463$ & 10.30 & .040 & 100 \\
\hline E10a & M62829 & Early growth response 1 & $3330 \pm 1222$ & $33,837 \pm 8606$ & 10.16 & .013 & 100 \\
\hline $\mathrm{A} 03 \mathrm{~h}$ & X59798 & Cyclin D1 & $62 \pm 26$ & $611 \pm 191$ & 9.89 & .029 & 75 \\
\hline D06j & X79067 & EGF-response factor 1 & $1422 \pm 255$ & $13,772 \pm 4690$ & 9.68 & .039 & 100 \\
\hline D13a & M55983 & Deoxyribonuclease I & $6 \pm 6$ & $52 \pm 18$ & 9.05 & .048 & 50 \\
\hline A09g & M35410 & Insulinlike growth factor binding protein 2 & $627 \pm 156$ & $5626 \pm 1679$ & 8.97 & .025 & 75 \\
\hline $\mathrm{F} 07 \mathrm{~m}$ & J05070 & MMP-9/gelatinase B & $151 \pm 26$ & $1306 \pm 367$ & 8.64 & .020 & 75 \\
\hline E07a & M36542 & POU domain class 2 transcription factor 2 & $12 \pm 7$ & $98 \pm 18$ & 8.33 & .004 & 100 \\
\hline B09g & U12535 & EGF receptor pathway substrate 8 & $44 \pm 27$ & $361 \pm 115$ & 8.10 & .037 & 75 \\
\hline Cogf & D12614 & Lymphotoxin $\alpha$ & $15 \pm 9$ & $120 \pm 23$ & 8.03 & .006 & 100 \\
\hline CO1f & L34075 & FK506 binding protein 12 (FRAP) & $32 \pm 8$ & $252 \pm 60$ & 7.99 & .011 & 100 \\
\hline E03h & M30257 & Vascular cell adhesion molecule 1 & $70 \pm 13$ & $545 \pm 81$ & 7.81 & .001 & 100 \\
\hline B03m & X80907 & PI-3-kinase, regulatory subunit (p85 $\beta$ ) & $32 \pm 16$ & $240 \pm 44$ & 7.45 & .004 & 100 \\
\hline $\mathrm{CO2e}$ & J03075 & PKC substrate $80 \mathrm{~K}-\mathrm{H}$ & $588 \pm 175$ & $4118 \pm 789$ & 7.00 & .005 & 100 \\
\hline E09l & D11086 & IL-2 receptor $\gamma$ & $262 \pm 75$ & $1787 \pm 535$ & 6.81 & .030 & 75 \\
\hline B02n & X08004 & $R A P 1 B$ (ras oncogene family) & $274 \pm 140$ & $1850 \pm 470$ & 6.75 & .018 & 75 \\
\hline C13a & L11329 & Dual-specificity phosphatase 2 (PAC-1) & $21 \pm 9$ & $140 \pm 32$ & 6.74 & .011 & 100 \\
\hline A04d & X56681 & jun $\mathrm{D}$ proto-oncogene & $228 \pm 43$ & $1502 \pm 503$ & 6.59 & .045 & 75 \\
\hline B14m & X16316 & vav-1 oncogene & $54 \pm 34$ & $352 \pm 114$ & 6.53 & .046 & 75 \\
\hline $\mathrm{C} 12 \mathrm{~b}$ & U14188 & Ephrin A4 & $51 \pm 5$ & $316 \pm 53$ & 6.20 & .003 & 100 \\
\hline $\mathrm{CO} f$ & U61166 & SH3 p17 protein & $63 \pm 9$ & $387 \pm 77$ & 6.19 & .006 & 100 \\
\hline $\mathrm{CO3a}$ & M31724 & Protein tyrosine phosphatase type 1 & $52 \pm 26$ & $324 \pm 92$ & 6.18 & .030 & 75 \\
\hline F13a & X14672 & $\mathrm{N}$-acetyltransferase 2 & $51 \pm 19$ & $314 \pm 49$ & 6.17 & .003 & 100 \\
\hline Co9e & AF076974 & Transform/transcript domain-associated protein & $175 \pm 37$ & $1079 \pm 114$ & 6.15 & $<.001$ & 100 \\
\hline A02f & D17517 & TYR03 protein tyrosine kinase & $75 \pm 29$ & $459 \pm 152$ & 6.15 & .047 & 75 \\
\hline B12d & M57230 & IL-6 signal transducer gp130 & $43 \pm 9$ & $261 \pm 86$ & 6.14 & .045 & 75 \\
\hline $\mathrm{C} 13 \mathrm{c}$ & M97935 & STAT-1 & $60 \pm 31$ & $358 \pm 21$ & 5.94 & $<.001$ & 100 \\
\hline $\mathrm{COBh}$ & U39613 & ICE-LAP3 & $22 \pm 13$ & $131 \pm 22$ & 5.81 & .006 & 75 \\
\hline C10d & M23379 & RAS p21 protein activator & $92 \pm 30$ & $521 \pm 112$ & 5.67 & .010 & 100 \\
\hline B10g & M15800 & mal, T-cell differentiation protein & $55 \pm 14$ & $302 \pm 64$ & 5.49 & .009 & 100 \\
\hline $\mathrm{C} 10 \mathrm{c}$ & X14454 & Interferon regulatory factor 1 & $119 \pm 24$ & $651 \pm 78$ & 5.49 & .001 & 100 \\
\hline F10i & K02770 & IL-1 $\beta$ & $642 \pm 119$ & $3472 \pm 1080$ & 5.41 & .040 & 100 \\
\hline C14e & M23410 & Junction plakoglobin & $104 \pm 22$ & $563 \pm 40$ & 5.39 & $<.001$ & 100 \\
\hline E11c & M97190 & Sp2 transcription factor & $146 \pm 7$ & $771 \pm 243$ & 5.28 & .042 & 100 \\
\hline $\mathrm{A} 04 \mathrm{~h}$ & D13639 & Cyclin D2 & $67 \pm 22$ & $336 \pm 16$ & 5.00 & $<.001$ & 100 \\
\hline $\mathrm{F} 13 \mathrm{~m}$ & M11233 & Cathepsin D & $3975 \pm 2371$ & $19,697 \pm 1763$ & 4.96 & .002 & 100 \\
\hline C13d & S76965 & $\begin{array}{l}\text { Cyclic adenosine monophosphate-dependent } \\
\text { protein kinase inhibitor } \alpha\end{array}$ & $58 \pm 21$ & $284 \pm 64$ & 4.88 & .015 & 100 \\
\hline $\operatorname{cog} d$ & X69550 & Rho GDP dissociation inhibitor $\alpha$ & $2949 \pm 938$ & $14,297 \pm 1549$ & 4.85 & .001 & 100 \\
\hline G31 & M11886 & MHC class I C & $3264 \pm 1153$ & $15,513 \pm 3565$ & 4.75 & .017 & 75 \\
\hline $\mathrm{B} 02 \mathrm{~g}$ & M16038 & v-yes-1 oncogene & $127 \pm 69$ & $602 \pm 162$ & 4.75 & .035 & 75 \\
\hline E03e & M64673 & Heat shock transcription factor 1 & $746 \pm 107$ & $3507 \pm 733$ & 4.70 & .010 & 100 \\
\hline E01e & L12579 & Cut-like 1 (Drosophila) & $293 \pm 55$ & $1352 \pm 306$ & 4.61 & .014 & 100 \\
\hline
\end{tabular}


TABLE 1. Continued

\begin{tabular}{|c|c|c|c|c|c|c|c|}
\hline Array code & $\begin{array}{l}\text { GenBank } \\
\text { reference }\end{array}$ & Gene or protein name & NTA & TAA & $\mathrm{A} / \mathrm{N}$ ratio & $P$ value & $\begin{array}{c}\text { Conservation } \\
(\%)\end{array}$ \\
\hline $\mathrm{E} 09 \mathrm{a}$ & M62810 & Mitochondrial transcription factor 1 & $115 \pm 39$ & $524 \pm 145$ & 4.58 & .034 & 75 \\
\hline $\mathrm{E} 12 \mathrm{e}$ & M96824 & Nucleobindin 1 & $2430 \pm 732$ & $10,831 \pm 2299$ & 4.46 & .013 & 100 \\
\hline E01f & U04847 & SWI/SNF-related member 1 & $615 \pm 114$ & $2605 \pm 347$ & 4.23 & .002 & 100 \\
\hline B05j & L31951 & Mitogen-activated protein kinase 9 & $70 \pm 23$ & $292 \pm 53$ & 4.18 & .008 & 75 \\
\hline Do9e & M65212 & Catechol-0-methyltransferase & $1376 \pm 458$ & $5711 \pm 1545$ & 4.15 & .036 & 75 \\
\hline D12d & AF016709 & Purinergic receptor $\mathrm{P} 2 \mathrm{X}$ & $18 \pm 11$ & $69 \pm 18$ & 3.93 & .048 & 75 \\
\hline $\mathrm{F} 14 \mathrm{~m}$ & U41766 & ADAM-9 & $230 \pm 48$ & $895 \pm 134$ & 3.88 & .003 & 100 \\
\hline E14g & J03132 & Intercellular adhesion molecule 1/CD54 & $1281 \pm 809$ & $4960 \pm 699$ & 3.87 & .014 & 50 \\
\hline A05h & M92287 & Cyclin D3 & $153 \pm 63$ & $588 \pm 39$ & 3.84 & .001 & 100 \\
\hline B04g & U07707 & $\begin{array}{l}\text { Epidermal growth factor receptor pathway } \\
\text { substrate } 15\end{array}$ & $162 \pm 46$ & $601 \pm 142$ & 3.71 & .025 & 100 \\
\hline F14l & U78095 & Serine protease inhibitor 2 & $454 \pm 164$ & $1681 \pm 406$ & 3.70 & .031 & 75 \\
\hline $\mathrm{C13e}$ & X61615 & Leukemia inhibitory factor receptor & $65 \pm 32$ & $230 \pm 41$ & 3.56 & .019 & 50 \\
\hline C11b & U56976 & Phosphodiesterase IB, calmodulin dependent & $61 \pm 35$ & $213 \pm 18$ & 3.51 & .008 & 50 \\
\hline B14h & U25265 & Mitogen-activated protein kinase 5 & $116 \pm 26$ & $393 \pm 108$ & 3.40 & .047 & 100 \\
\hline A09h & M77234 & Ribosomal protein S3A & $6819 \pm 3384$ & $22,853 \pm 4397$ & 3.35 & .028 & 75 \\
\hline $\mathrm{A} 02 \mathrm{~h}$ & M25753 & Cyclin B1 & $136 \pm 29$ & $453 \pm 107$ & 3.32 & .029 & 75 \\
\hline C11g & X76981 & Adenosine $\mathrm{A} 3$ receptor & $118 \pm 38$ & $386 \pm 92$ & 3.28 & .035 & 75 \\
\hline $\mathrm{C} 12 \mathrm{a}$ & M63960 & Protein phosphatase-1, catalytic subunit $\alpha$ & $665 \pm 196$ & $2125 \pm 363$ & 3.20 & .012 & 100 \\
\hline $\mathrm{CO8e}$ & X75621 & Tuberous sclerosis 2 & $250 \pm 51$ & $793 \pm 89$ & 3.17 & .002 & 100 \\
\hline $\mathrm{CO} \mathrm{i}$ & X04106 & Calpain 4 , small subunit $(30 \mathrm{kd})$ & $6392 \pm 1247$ & $20,202 \pm 3665$ & 3.16 & .012 & 100 \\
\hline B05e & U12140 & Neurotrophic tyrosine kinase receptor type 2 & $61 \pm 23$ & $191 \pm 28$ & 3.14 & .011 & 75 \\
\hline $\mathrm{C} 12 \mathrm{c}$ & L19067 & $v-r e /$ (nuclear factor $\kappa$ B related) p65 & $196 \pm 34$ & $613 \pm 131$ & 3.13 & .022 & 75 \\
\hline E13e & U02326 & Neuregulin 1 & $90 \pm 15$ & $280 \pm 75$ & 3.11 & .048 & 100 \\
\hline $\mathrm{CO3h}$ & X96586 & Sphingomyelinase activation-associated factor & $171 \pm 50$ & $532 \pm 125$ & 3.11 & .037 & 75 \\
\hline B06h & U09578 & $\begin{array}{l}\text { Mitogen-activated protein kinase-activated } \\
\text { protein kinase } 3\end{array}$ & $53 \pm 26$ & $158 \pm 21$ & 2.98 & .020 & 50 \\
\hline $\mathrm{A} 05 \mathrm{c}$ & M80359 & $\begin{array}{l}\text { Mitogen-activated protein/microtubule affinity- } \\
\text { regulating kinase } 3\end{array}$ & $213 \pm 59$ & $632 \pm 157$ & 2.97 & .047 & 75 \\
\hline $\mathrm{CO} 2 \mathrm{~g}$ & Y09392 & TNF receptor superfamily member 12 & $139 \pm 34$ & $402 \pm 73$ & 2.88 & .017 & 75 \\
\hline $\mathrm{CO}$ & U20537 & Caspase 6 & $78 \pm 20$ & $219 \pm 30$ & 2.81 & .008 & 75 \\
\hline $\mathrm{A} 04 \mathrm{i}$ & M14505 & Cyclin-dependent kinase 4 & $275 \pm 78$ & $751 \pm 156$ & 2.73 & .034 & 75 \\
\hline B07n & M28212 & RAB6 & $243 \pm 49$ & $641 \pm 145$ & 2.64 & .040 & 75 \\
\hline CO7e & U17032 & $\begin{array}{l}\text { Rho guanosine triphosphatase activating } \\
\text { protein } 5\end{array}$ & $86 \pm 15$ & $225 \pm 49$ & 2.62 & .035 & 75 \\
\hline CO7j & X86779 & Fas-activated serine/threonine kinase & $344 \pm 72$ & $884 \pm 125$ & 2.57 & .010 & 100 \\
\hline D10l & U58198 & IL enhancer binding factor 1 & $126 \pm 25$ & $320 \pm 70$ & 2.53 & .041 & 50 \\
\hline E14e & U03494 & Transcription factor CP2 & $122 \pm 29$ & $304 \pm 68$ & 2.48 & .049 & 50 \\
\hline E06i & M59911 & Integrin $\alpha_{3}$ & $163 \pm 32$ & $397 \pm 84$ & 2.44 & .040 & 75 \\
\hline E05j & M23197 & CD33 antigen (gp67) & $109 \pm 10$ & $264 \pm 46$ & 2.42 & .016 & 100 \\
\hline $\mathrm{CO4h}$ & U13021 & Caspase 2 & $88 \pm 21$ & $209 \pm 21$ & 2.38 & .006 & 75 \\
\hline $\mathrm{A} 04 \mathrm{f}$ & $\mathrm{X} 16416$ & $v-a b l$ & $116 \pm 27$ & $274 \pm 25$ & 2.36 & .006 & 100 \\
\hline C10b & U40370 & Phosphodiesterase $1 \mathrm{~A}$, calmodulin dependent & $185 \pm 50$ & $436 \pm 89$ & 2.36 & .049 & 75 \\
\hline F07k & X87212 & Cathepsin C & $916 \pm 281$ & $2138 \pm 355$ & 2.33 & .036 & 50 \\
\hline E06k & U11814 & Keratinocyte growth factor receptor & $66 \pm 12$ & $151 \pm 14$ & 2.28 & .003 & 100 \\
\hline D10k & AF069733 & Transcriptional adaptor 3 & $185 \pm 20$ & $400 \pm 85$ & 2.16 & .048 & 50 \\
\hline F13c & M22489 & Bone morphogenetic protein 2 & $198 \pm 67$ & $405 \pm 47$ & 2.05 & .044 & 50 \\
\hline $\mathrm{CO} 2$ & X98093 & Polymerase (DNA directed) $\gamma$ & $183 \pm 28$ & $366 \pm 53$ & 2.00 & .022 & 75 \\
\hline F12j & M24398 & Parathymosin & $6374 \pm 1193$ & $12,240 \pm 1778$ & 1.92 & .034 & 75 \\
\hline E04j & M21097 & CD19 antigen & $91 \pm 17$ & $172 \pm 10$ & 1.89 & .007 & 75 \\
\hline E01j & X87838 & Catenin $\beta 1$ (88 kd) & $353 \pm 59$ & $567 \pm 54$ & 1.61 & .036 & 50 \\
\hline F06b & M11717 & Heat shock 70 kd protein $1 \mathrm{~A}$ & $5558 \pm 990$ & $8556 \pm 678$ & 1.54 & .047 & 50 \\
\hline E11m & U77604 & Microsomal glutathione S-transferase 2 & $1448 \pm 44$ & $1040 \pm 141$ & 0.72 & .032 & 0 \\
\hline Co6n & U07418 & muth homolog 1 (Escherichia coli) & $36,628 \pm 4866$ & $21,048 \pm 2038$ & 0.57 & .026 & 25 \\
\hline E121 & U00672 & IL-10 receptor $\alpha$ & $180 \pm 15$ & $69 \pm 24$ & 0.38 & .008 & 100 \\
\hline C05k & U32944 & Dynein cytoplasmic light polypeptide & $13,323 \pm 983$ & $4965 \pm 1028$ & 0.37 & .001 & 100 \\
\hline A08I & M63618 & Bullous pemphigoid antigen $1(230 / 240 \mathrm{kd})$ & $731 \pm 158$ & $227 \pm 18$ & 0.31 & .019 & 0 \\
\hline F01g & M96956 & Teratocarcinoma-derived growth factor 3 & $1296 \pm 439$ & $151 \pm 59$ & 0.12 & .041 & 25 \\
\hline D11h & U32376 & Discs, large (Drosophila) homolog 2 & $70 \pm 23$ & $6 \pm 6$ & 0.09 & .034 & 75 \\
\hline
\end{tabular}

$A / N$, Abnormal/normal ratio. 
TABLE 2. One hundred four genes exhibiting altered expression in AAAs

\begin{tabular}{|c|c|c|c|c|c|c|c|}
\hline $\begin{array}{l}\text { Array } \\
\text { code }\end{array}$ & $\begin{array}{l}\text { GenBank } \\
\text { reference }\end{array}$ & Gene or protein name & NAA & AAA & $\mathrm{A} / \mathrm{N}$ ratio & $P$ value & $\begin{array}{c}\text { Conservation } \\
(\%)\end{array}$ \\
\hline F07m & J05070 & MMP-9/gelatinase B & $96 \pm 81$ & $8317 \pm 2590$ & 86.52 & .019 & 100 \\
\hline B04d & L25259 & CD86 antigen (B7-2 antigen) & $34 \pm 34$ & $1463 \pm 237$ & 43.42 & .001 & 100 \\
\hline E10f & L36720 & Bystin-like & $31 \pm 31$ & $1277 \pm 484$ & 40.77 & .042 & 75 \\
\hline $\mathrm{B} 04 \mathrm{c}$ & M12529 & Apolipoprotein $\mathrm{E}$ & $993 \pm 570$ & $14,459 \pm 4144$ & 14.56 & .018 & 100 \\
\hline E03i & M15395 & Integrin $\beta_{2}$ & $256 \pm 191$ & $3278 \pm 707$ & 12.79 & .006 & 100 \\
\hline B05k & U43408 & Nonreceptor tyrosine kinase 1 & $65 \pm 65$ & $767 \pm 235$ & 11.87 & .028 & 100 \\
\hline B03j & U09607 & Janus kinase 3 & $359 \pm 157$ & $2999 \pm 968$ & 8.35 & .036 & 100 \\
\hline $\mathrm{E} 09 \mathrm{~g}$ & M73780 & Integrin $\beta_{8}$ & $430 \pm 329$ & $3443 \pm 749$ & 8.00 & .010 & 100 \\
\hline $\mathrm{F} 14 \mathrm{~g}$ & Y00787 & IL-8 & $2150 \pm 950$ & $15,494 \pm 5313$ & 7.21 & .048 & 75 \\
\hline B05i & D10495 & PKC- $\delta$ & $458 \pm 282$ & $3226 \pm 994$ & 7.04 & .037 & 75 \\
\hline E08c & X55122 & GATA-3 & $553 \pm 292$ & $3774 \pm 736$ & 6.83 & .007 & 100 \\
\hline E04h & M30640 & Selectin E & $392 \pm 164$ & $2566 \pm 615$ & 6.54 & .014 & 75 \\
\hline $\mathrm{CO} \mathrm{j}$ & M63167 & $\mathrm{v}$-akt (rac protein kinase $\alpha$ ) & $260 \pm 187$ & $1698 \pm 328$ & 6.53 & .009 & 100 \\
\hline B02j & M35203 & Janus kinase 1 & $263 \pm 100$ & $1650 \pm 546$ & 6.27 & .046 & 75 \\
\hline E10b & M97676 & msh homolog 1 (Drosophila) & $1249 \pm 335$ & $7725 \pm 2032$ & 6.19 & .020 & 100 \\
\hline $\mathrm{B} 02 \mathrm{k}$ & AJ000512 & Serum glucocorticoid-regulated kinase & $590 \pm 194$ & $3478 \pm 907$ & 5.89 & .021 & 75 \\
\hline E02i & $\mathrm{L} 12002$ & Integrin $\alpha_{4}$ & $256 \pm 256$ & $1462 \pm 349$ & 5.72 & .032 & 50 \\
\hline E01c & U08015 & Nuclear factor of activated T cells & $295 \pm 91$ & $1659 \pm 521$ & 5.63 & .042 & 75 \\
\hline E01d & U43188 & E74-like factor 2 & $345 \pm 164$ & $1892 \pm 521$ & 5.48 & .030 & 100 \\
\hline $\mathrm{C} 04 \mathrm{k}$ & U45880 & Baculoviral IAP repeat-containing 4 & $278 \pm 98$ & $1512 \pm 435$ & 5.44 & .032 & 75 \\
\hline A11I & M81750 & Myeloid cell nuclear differentiation antigen & $2331 \pm 911$ & $12,077 \pm 708$ & 5.18 & $<.001$ & 100 \\
\hline E06e & D28468 & Albumin $D$ box-binding protein & $1429 \pm 661$ & $7399 \pm 722$ & 5.18 & .001 & 100 \\
\hline E04a & M16937 & Homeo box $\mathrm{B} 7$ & $1121 \pm 604$ & $5650 \pm 1728$ & 5.04 & .048 & 75 \\
\hline B13d & D10924 & CXC chemokine receptor-4 (fusin) & $2254 \pm 588$ & $11,172 \pm 1767$ & 4.96 & .003 & 100 \\
\hline $\mathrm{E} 05 \mathrm{~g}$ & D83542 & Cadherin 15 (M-cadherin) & $571 \pm 465$ & $2704 \pm 722$ & 4.73 & .048 & 50 \\
\hline E06h & M34064 & Cadherin 2 (N-cadherin) & $435 \pm 264$ & $2018 \pm 456$ & 4.64 & .024 & 75 \\
\hline F08k & X07549 & Cathepsin $\mathrm{H}$ & $2914 \pm 1216$ & $13,310 \pm 3460$ & 4.57 & .030 & 75 \\
\hline $\mathrm{C} 10 \mathrm{a}$ & L14778 & Calcineurin A $\alpha$ & $1411 \pm 717$ & $6394 \pm 1268$ & 4.53 & .014 & 75 \\
\hline $\mathrm{F} 12 f$ & M74178 & Macrophage stimulating 1 & $2307 \pm 906$ & $10297 \pm 1592$ & 4.46 & .005 & 100 \\
\hline $\mathrm{B} 07 \mathrm{~g}$ & AF055581 & Lymphocyte adaptor protein & $647 \pm 267$ & $2865 \pm 634$ & 4.42 & .018 & 75 \\
\hline $\mathrm{E} 05 \mathrm{c}$ & U10324 & IL enhancer binding factor 3 (90 kd) & $844 \pm 440$ & $3712 \pm 705$ & 4.40 & .014 & 75 \\
\hline $\mathrm{E} 09 \mathrm{~b}$ & M97287 & Special AT-rich sequence binding protein 1 & $1226 \pm 262$ & $5290 \pm 1192$ & 4.31 & .016 & 100 \\
\hline B01e & U08839 & Urinary-type plasminogen activator receptor & $500 \pm 418$ & $2155 \pm 305$ & 4.31 & .019 & 50 \\
\hline E11g & M14219 & Decorin & $3497 \pm 1447$ & $14,855 \pm 4031$ & 4.25 & .038 & 75 \\
\hline E08d & M58603 & Nuclear factor $\kappa$ B enhancer p105 & $805 \pm 330$ & $3234 \pm 534$ & 4.02 & .008 & 75 \\
\hline E14i & Y00796 & Integrin $\alpha_{\mathrm{L}}$ (CD11a antigen) & $3269 \pm 898$ & $12,634 \pm 1824$ & 3.86 & .004 & 100 \\
\hline E06d & AF072825 & raf-responsive zincfinger protein & $491 \pm 293$ & $1893 \pm 321$ & 3.86 & .018 & 75 \\
\hline E07b & M93255 & Friend leukemia virus integration 1 & $3564 \pm 958$ & $13,673 \pm 2286$ & 3.84 & .007 & 100 \\
\hline B06d & M62424 & Coagulation factor II (thrombin) receptor & $2657 \pm 929$ & $10,182 \pm 593$ & 3.83 & $>.001$ & 100 \\
\hline A09c & K00650 & $v-f o s$ & $2290 \pm 819$ & $8080 \pm 1584$ & 3.53 & .018 & 75 \\
\hline B05j & L31951 & Mitogen-activated protein kinase 9 & $479 \pm 195$ & $1629 \pm 427$ & 3.40 & .050 & 50 \\
\hline A12 & D38305 & Transducer of ERBB2-1 & $935 \pm 512$ & $3170 \pm 679$ & 3.39 & .039 & 50 \\
\hline $\mathrm{B} 02 \mathrm{~m}$ & U86453 & PI-3-kinase $\delta$ polypeptide & $626 \pm 246$ & $2103 \pm 494$ & 3.36 & .037 & 75 \\
\hline B05l & U08316 & Ribosomal S6 kinase 3 & $1095 \pm 440$ & $3671 \pm 595$ & 3.35 & .013 & 75 \\
\hline E09d & D45132 & Zinc-finger DNA-binding protein & $519 \pm 156$ & $1735 \pm 164$ & 3.34 & .002 & 100 \\
\hline B05d & D10925 & Chemokine (C-C motif) receptor 1 & $419 \pm 194$ & $1343 \pm 273$ & 3.21 & .033 & 75 \\
\hline $\mathrm{CO} 2 \mathrm{k}$ & L09210 & $\begin{array}{l}\text { Inducible nitric oxide synthase (nitric oxide } \\
\text { synthase 2) }\end{array}$ & $381 \pm 196$ & $1168 \pm 242$ & 3.07 & .045 & 50 \\
\hline B03I & L07597 & Ribosomal S6 kinase 1 & $963 \pm 413$ & $2914 \pm 420$ & 3.03 & .016 & 75 \\
\hline $\mathrm{E} 08 \mathrm{~b}$ & M96944 & Paired box gene 5 & $1491 \pm 566$ & $4393 \pm 600$ & 2.95 & .013 & 50 \\
\hline B04k & L32976 & Mitogen-activated protein kinase 11 & $1474 \pm 878$ & $4337 \pm 198$ & 2.94 & .020 & 0 \\
\hline $\mathrm{B} 04 \mathrm{~m}$ & U78576 & PI-4-phosphate 5-kinase type $1 \alpha$ & $684 \pm 367$ & $2010 \pm 324$ & 2.94 & .035 & 50 \\
\hline $\mathrm{E} 14 \mathrm{~g}$ & J03132 & Intercellular adhesion molecule 1/CD54 & $6563 \pm 2678$ & $18,441 \pm 2215$ & 2.81 & .014 & 50 \\
\hline F14j & Z71621 & Wingless-type MMTV integration site 2B & $3676 \pm 1447$ & $10,078 \pm 1651$ & 2.74 & .027 & 75 \\
\hline F13k & D45248 & Proteasome activator subunit 2 & $4268 \pm 1256$ & $11,121 \pm 2172$ & 2.61 & .034 & 75 \\
\hline E07e & L11672 & Zinc finger protein 91 (HPF7, HTF10) & $3639 \pm 1152$ & $9444 \pm 683$ & 2.60 & .005 & 75 \\
\hline $\mathrm{B} 07 \mathrm{~m}$ & X15014 & v-ral & $1573 \pm 296$ & $3966 \pm 708$ & 2.52 & .021 & 75 \\
\hline B05n & M28211 & RAB4 (ras oncogene family) & $335 \pm 107$ & $823 \pm 150$ & 2.46 & .038 & 50 \\
\hline F06d & M29645 & Insulinlike growth factor 2 (somatomedin A) & $1221 \pm 433$ & $2954 \pm 358$ & 2.42 & .022 & 25 \\
\hline
\end{tabular}


TABLE 2. Continued

\begin{tabular}{|c|c|c|c|c|c|c|c|}
\hline $\begin{array}{l}\text { Array } \\
\text { code }\end{array}$ & $\begin{array}{c}\text { GenBank } \\
\text { reference }\end{array}$ & Gene or protein name & NAA & AAA & $\mathrm{A} / \mathrm{N}$ ratio & $P$ value & $\begin{array}{c}\text { Conservation } \\
(\%)\end{array}$ \\
\hline E05b & M87503 & Interferon-stimulated transcription factor $3 \gamma$ & $5644 \pm 1379$ & $13,606 \pm 966$ & 2.41 & .003 & 100 \\
\hline E03c & U08853 & Transcription factor LCR-F1 & $884 \pm 310$ & $2080 \pm 244$ & 2.35 & .023 & 25 \\
\hline $\mathrm{B} 02 \mathrm{~g}$ & M16038 & v-yes-1 oncogene & $1707 \pm 587$ & $3953 \pm 534$ & 2.32 & .030 & 25 \\
\hline E08h & M59040 & CD44 antigen & $3073 \pm 991$ & $7094 \pm 521$ & 2.31 & .011 & 25 \\
\hline E02c & U08191 & $\mathrm{R} \kappa \mathrm{B}$ & $1264 \pm 117$ & $2857 \pm 378$ & 2.26 & .007 & 100 \\
\hline $\mathrm{F} 10 \mathrm{e}$ & M21121 & RANTES & $7363 \pm 1838$ & $15,804 \pm 2850$ & 2.15 & .047 & 50 \\
\hline E01k & M59818 & CSF-3 receptor & $2319 \pm 167$ & $4320 \pm 547$ & 1.86 & .013 & 100 \\
\hline B12d & M57230 & IL-6 signal transducer gp130 & $3567 \pm 536$ & $1377 \pm 579$ & 0.39 & .032 & 75 \\
\hline D01n & L04282 & Zinc-finger protein 148 & $4260 \pm 225$ & $1677 \pm 679$ & 0.39 & .011 & 50 \\
\hline D11n & D26120 & Zinc-finger protein 162 & $2567 \pm 525$ & $977 \pm 382$ & 0.38 & .050 & 25 \\
\hline D07l & M73077 & Glucocorticoid receptor DNA binding factor 1 & $2510 \pm 434$ & $896 \pm 394$ & 0.36 & .033 & 50 \\
\hline D09j & U65928 & COP9 subunit 5 & $4236 \pm 1085$ & $1288 \pm 484$ & 0.30 & .048 & 25 \\
\hline B08m & X06820 & ras homolog gene family, member $\mathrm{B}$ & $15,578 \pm 3944$ & $4710 \pm 1925$ & 0.30 & .048 & 0 \\
\hline B08n & U02081 & Guanine nucleotide regulatory protein & $4416 \pm 1051$ & $1235 \pm 614$ & 0.28 & .040 & 25 \\
\hline D03i & U18840 & Myelin oligodendrocyte glycoprotein & $2782 \pm 645$ & $769 \pm 493$ & 0.28 & .048 & 50 \\
\hline D07j & L01042 & TATA element modulatory factor 1 & $2915 \pm 749$ & $758 \pm 439$ & 0.26 & .047 & 50 \\
\hline A09i & M84489 & Mitogen-activated protein kinase 1 & $1686 \pm 133$ & $437 \pm 336$ & 0.26 & .014 & 75 \\
\hline $\mathrm{D} 12 \mathrm{~m}$ & L14754 & Immunoglobulin $\mu$ binding protein 2 & $1859 \pm 469$ & $428 \pm 247$ & 0.23 & .036 & 50 \\
\hline B09d & L37882 & Frizzled homolog 2 (Drosophila) & $905 \pm 126$ & $198 \pm 159$ & 0.22 & .013 & 75 \\
\hline $\mathrm{B} 14 \mathrm{~h}$ & U25265 & Mitogen-activated protein kinase 5 & $1860 \pm 370$ & $392 \pm 220$ & 0.21 & .014 & 50 \\
\hline $\mathrm{F} 12 \mathrm{l}$ & Z81326 & Protease inhibitor 12 (neuroserpin) & $1511 \pm 293$ & $305 \pm 305$ & 0.20 & .029 & 75 \\
\hline $\mathrm{A} 08 \mathrm{~g}$ & M28882 & Melanoma adhesion molecule & $8631 \pm 2691$ & $1687 \pm 782$ & 0.20 & .048 & 25 \\
\hline D10l & U58198 & IL enhancer binding factor- 1 & $1738 \pm 475$ & $333 \pm 155$ & 0.19 & .031 & 25 \\
\hline D13j & J03161 & Serum response factor & $2648 \pm 312$ & $496 \pm 279$ & 0.19 & .002 & 100 \\
\hline $\mathrm{D} 13 \mathrm{~m}$ & M88163 & SWI/SNF homolog & $2547 \pm 422$ & $459 \pm 302$ & 0.18 & .007 & 75 \\
\hline $\mathrm{D} 05 \mathrm{l}$ & M21535 & v-ets (avian erythroblastosis virus oncogene) & $3703 \pm 863$ & $666 \pm 431$ & 0.18 & .020 & 50 \\
\hline D07k & AF069736 & PCAF-associated factor $65 \beta$ & $2215 \pm 530$ & $332 \pm 231$ & 0.15 & .017 & 50 \\
\hline D10e & X52836 & Tryptophan hydroxylase & $11,706 \pm 1092$ & $1424 \pm 517$ & 0.12 & $<.001$ & 100 \\
\hline B10e & L36645 & EphA4 & $866 \pm 291$ & $97 \pm 97$ & 0.11 & .046 & 75 \\
\hline $\mathrm{D} 01 \mathrm{~b}$ & M60974 & Growth arrest and DNA damage inducible 45 & $9267 \pm 2748$ & $1027 \pm 799$ & 0.11 & .028 & 25 \\
\hline F05j & L15344 & IL-14 & $514 \pm 145$ & $49 \pm 49$ & 0.10 & .023 & 75 \\
\hline B10k & M34181 & $\begin{array}{l}\text { Cyclic adenosine monophosphate-dependent } \\
\text { protein kinase } \beta\end{array}$ & $1806 \pm 367$ & $154 \pm 104$ & 0.09 & .005 & 75 \\
\hline D04n & Z30094 & General transcription factor IIH polypeptide 2 & $2069 \pm 712$ & $159 \pm 151$ & 0.08 & .039 & 50 \\
\hline F11l & D38595 & Plasma kallikrein-sensitive glycoprotein & $2216 \pm 596$ & $168 \pm 144$ & 0.08 & .016 & 50 \\
\hline $\mathrm{D} 10 \mathrm{~m}$ & M95809 & General transcription factor IIH polypeptide 1 & $2523 \pm 350$ & $180 \pm 97$ & 0.07 & .001 & 100 \\
\hline $\mathrm{D} 14 \mathrm{k}$ & L19871 & Activating transcription factor 3 & $3866 \pm 1008$ & $252 \pm 252$ & 0.07 & .013 & 75 \\
\hline $\mathrm{B} 12 \mathrm{~g}$ & U48959 & Myosin light chain kinase & $16,148 \pm 4217$ & $770 \pm 287$ & 0.05 & .011 & 25 \\
\hline B11g & $\mathrm{D} 84476$ & Mitogen-activated protein kinase 5 & $3229 \pm 1203$ & $137 \pm 81$ & 0.04 & .043 & 50 \\
\hline B11I & L36151 & PI-4-kinase $\alpha$ & $360 \pm 57$ & $14 \pm 14$ & 0.04 & .001 & 100 \\
\hline $\mathrm{F} 13 \mathrm{a}$ & $\mathrm{X} 14672$ & $\mathrm{~N}$-acetyltransferase-2 & $827 \pm 320$ & $25 \pm 25$ & 0.03 & .047 & 75 \\
\hline $\mathrm{B} 13 \mathrm{~g}$ & X69490 & Titin & $2412 \pm 686$ & $70 \pm 57$ & 0.03 & .014 & 50 \\
\hline D11j & U35143 & Retinoblastoma-binding protein 7 & $2351 \pm 516$ & $60 \pm 60$ & 0.03 & .005 & 100 \\
\hline $\mathrm{B} 12 \mathrm{e}$ & L11695 & Transforming growth factor $\beta$ receptor I & $1715 \pm 599$ & $35 \pm 35$ & 0.02 & .031 & 75 \\
\hline $\mathrm{D} 13 \mathrm{k}$ & U00115 & B-cell CLL/lymphoma-6 & $2004 \pm 517$ & $35 \pm 34$ & 0.02 & .009 & 50 \\
\hline $\mathrm{D} 05 \mathrm{~g}$ & U26662 & Neuronal pentraxin II & $2413 \pm 880$ & $27 \pm 23$ & 0.01 & .035 & 50 \\
\hline F01m & D45027 & $\mathrm{R} 3 \mathrm{H}$ domain & $498 \pm 201$ & $0 \pm 0$ & 0 & .048 & 100 \\
\hline
\end{tabular}

$A / N$, Abnormal/normal ratio.

AAAs and NAA, including MMP-9/gelatinase B (86-fold), CD86/B7-2 antigen (43-fold), bystin-like (41-fold), apolipoprotein E (15-fold), integrin $\beta_{2}$ (13-fold), and nonreceptor tyrosine kinase 1 (12-fold). Sixty-six of the 104 genes (63\%) exhibited the alterations described in at least 3 of the 4 individual AAA specimens, including 50 of the 66 genes (76\%) exhibiting increased expression and 17 of the 39 genes (44\%) exhibiting decreased expression (Table 2).
Parallel analyses between aneurysmal and normal aortic tissues from each location are summarized by the Venn diagram shown in Figure 3, illustrating that the patterns of altered gene expression were quite dissimilar between TAAs and AAAs. It is notable that quantitative increases in expression for 97 genes were found to be unique to TAAs, whereas increases in expression for 61 genes were found to be unique to AAAs; similarly, decreases in expression for 7 
genes were unique to TAAs and decreases in 35 gene products were unique to AAAs. Although 8 additional transcripts were significantly altered in both TAAs and AAAs, these alterations were directionally concordant for only 4 genes: MMP-9/gelatinase B, v-yes-1, mitogen-activated protein kinase-9, and intracellular adhesion molecule 1/CD54 (all increased in both TAAs and AAAs). In contrast, the remaining genes were altered in a directionally discordant manner, with all 4 being significantly increased in TAAs and significantly decreased in AAAs (N-acetyltransferase-2, IL-6 signal transducer gp130, mitogen-activated protein kinase kinase-5, and IL enhancer binding factor-1).

\section{RT-qPCR}

To validate the results of cDNA microarray analysis, the patterns of messenger RNA expression for a series of selected genes were independently examined with real-time RT-qPCR. As shown in Table 3, this revealed significant increases in expression of MMP-9/gelatinase B and v-yes-1 oncogene in both TAAs and AAAs; increased expression of TNF- $\alpha$, IL- $1 \beta$, vascular cell adhesion molecule 1 , and cathepsin D in TAAs but not in AAAs; increased expression of apolipoprotein E and IL-8 in AAAs but not in TAAs; and increased expression of IL-6 signal transducer gp130 in TAAs with decreased expression in AAAs. In each case, the significance and magnitude of the alterations in expression as detected by RT-qPCR corresponded with the results of the microarray analysis. Thus there was a high degree of consistency between the quantitative results obtained with the two independent techniques.

\section{Discussion}

To better understand cellular and molecular changes that accompany aneurysm development, cDNA microarrays have been used to profile differences in gene expression between normal human aorta and AAAs. ${ }^{33,34}$ To the best of our knowledge, this investigation represents the first application of high-throughput transcriptional profiling to degenerative aneurysms of the ascending thoracic aorta, thereby providing some initial insights into molecular similarities and differences that may exist between TAAs and AAAs.

The most important observations arising from this study are as follows: (1) TAAs are characterized by significant alterations in expression for at least 112 genes relative to NTA; (2) the altered pattern of gene expression observed in TAAs is distinguishable from that observed in AAAs with respect to at least 208 genes, of which 101 are increased and 7 decreased in TAAs but not in AAAs and 61 are increased and 39 decreased in AAAs but not TAAs; (3) at least 8 genes exhibit altered expression in both TAAs and AAAs, including 4 with directionally concordant and 4 with directionally discordant changes; and (4) the greatest increases in

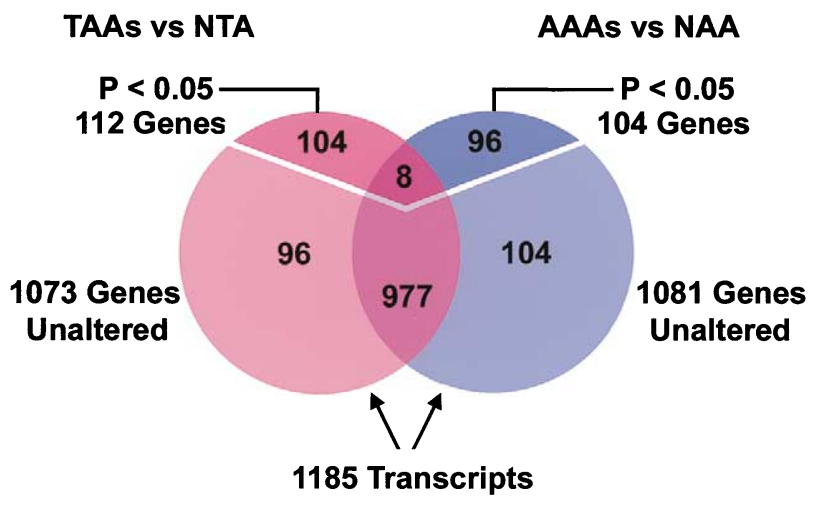

Figure 3. Number and distribution of genes exhibiting altered levels of expression in aortic aneurysms. Venn diagram showing number and distribution of $\mathbf{1 1 8 5}$ genes for which significantly altered $(P<.05)$ or unaltered $(P>.05)$ levels of expression were detected in TAAs versus NTA (red) and in AAAs versus NAA (blue) by parametric comparisons test. Numbers of genes exhibiting altered or unchanged levels of expression in both conditions are illustrated by areas of overlap (purple).

gene expression in TAAs were observed for the $\zeta$ and $\theta$ isoforms of PKC, uracil-DNA glycosylase (a DNA repair enzyme), lymphotoxin- $\beta$, TNF- $\alpha$, and CD27 (TNF receptor superfamily member-7), whereas the greatest changes in AAAs were for MMP-9/gelatinase B, CD86/B7-2 antigen, bystin-like, apolipoprotein $\mathrm{E}$, integrins $\beta_{2}$ and $\beta_{8}$, nonreceptor tyrosine kinase 1 , Janus kinase 3 , IL-8, and PKC- $\delta$. These findings support the hypothesis that TAAs and AAAs are fundamentally different pathophysiologic entities at a molecular level, probably reflecting distinct mechanisms of disease.

In a study of this nature, it is tempting to speculate that individual genes exhibiting altered levels of expression in aneurysmal tissues might be related to the pathophysiologic events underlying aneurysm formation. However, it is important to emphasize first that in this study we examined only established "end-stage" aneurysmal tissues from lesions advanced enough to require elective repair, and second that these aneurysmal tissues were evaluated against normal aortic tissues from comparatively young, healthy, cadaveric organ transplant donors as control preparations. The relative levels of gene expression found in these tissues thus may reflect alterations related to differences in age, microscopic atherosclerotic vascular disease, hemodynamic stresses, and other systemic factors, as well as the presence of aneurysmal degeneration. Furthermore, the alterations described in these established aneurysms do not necessarily provide insight into transcriptional alterations that might occur at earlier stages of disease, only those present in lesions that have enlarged enough to require repair. Although altered gene expression in these tissues may actually be more relevant to the potential clinical complications of 
TABLE 3. Changes in aortic wall gene expression measured by RT-qPCR versus cDNA microarrays ( $\mathrm{n}=\mathbf{9}$ genes)

\begin{tabular}{|c|c|c|c|c|}
\hline Gene or protein name & Thoracic & $P$ value & Abdominal & $P$ value \\
\hline \multicolumn{5}{|l|}{ MMP-9/gelatinase B } \\
\hline Aneurysmal expression (mean $\pm S D$, arbitrary units) & $2.71 \pm 0.34 \times 10^{-2}$ & & $1.16 \pm 0.20 \times 10^{-1}$ & \\
\hline Normal expression (mean $\pm S D$, arbitrary units) & $0.86 \pm 0.34 \times 10^{-2}$ & & $0.10 \pm 0.07 \times 10^{-1}$ & \\
\hline RT-qPCR aneurysmal/normal ratio & 3.13 & $<.001$ & 11.8 & $<.001$ \\
\hline Microarray aneurysmal/normal ratio & 8.64 & .020 & 86.5 & .019 \\
\hline \multicolumn{5}{|l|}{ IL-6 signal transducer gp130 } \\
\hline Aneurysmal expression (mean $\pm S D$, arbitrary units) & $5.74 \pm 0.85 \times 10^{1}$ & & $6.02 \pm 0.93 \times 10^{1}$ & \\
\hline Normal expression (mean $\pm S D$, arbitrary units) & $3.54 \pm 0.56 \times 10^{1}$ & & $1.13 \pm 0.21 \times 10^{2}$ & \\
\hline RT-qPCR aneurysmal/normal ratio & 1.62 & .041 & 0.53 & .038 \\
\hline Microarray aneurysmal/normal ratio & 6.14 & .045 & 0.39 & .032 \\
\hline \multicolumn{5}{|l|}{$\mathrm{v}$-yes-1 oncogene } \\
\hline Aneurysmal expression (mean $\pm S D$, arbitrary units) & $7.11 \pm 0.93 \times 10^{-1}$ & & $8.68 \pm 1.12 \times 10^{-2}$ & \\
\hline Normal expression (mean $\pm S D$, arbitrary units) & $4.21 \pm 0.69 \times 10^{-1}$ & & $2.73 \pm 0.74 \times 10^{-2}$ & \\
\hline RT-qPCR aneurysmal/normal ratio & 1.69 & .019 & 3.17 & $<.001$ \\
\hline Microarray aneurysmal/normal ratio & 4.75 & .035 & 2.32 & .030 \\
\hline \multicolumn{5}{|l|}{ Apopliporotein $\mathrm{E}$} \\
\hline Aneurysmal expression (mean $\pm S D$, arbitrary units) & $5.71 \pm 1.29 \times 10^{0}$ & & $8.77 \pm 1.98 \times 10^{-1}$ & \\
\hline Normal expression (mean $\pm S D$, arbitrary units) & $2.33 \pm 1.39 \times 10^{0}$ & & $7.05 \pm 1.51 \times 10^{-2}$ & \\
\hline RT-qPCR aneurysmal/normal ratio & 2.45 & $>.05$ & 12.44 & $<.001$ \\
\hline Microarray aneurysmal/normal ratio & 2.69 & $>.05$ & 14.56 & .018 \\
\hline \multicolumn{5}{|l|}{ IL-8 } \\
\hline Aneurysmal expression (mean $\pm \mathrm{SD}$, arbitrary units) & $3.33 \pm 0.30 \times 10^{0}$ & & $1.16 \pm 0.23 \times 10^{-1}$ & \\
\hline Normal expression (mean $\pm S D$, arbitrary units) & $5.80 \pm 0.15 \times 10^{0}$ & & $5.17 \pm 1.55 \times 10^{-2}$ & \\
\hline RT-qPCR aneurysmal/normal ratio & 0.57 & $>.05$ & 2.24 & $<.001$ \\
\hline Microarray aneurysmal/normal ratio & 1.01 & $>.05$ & 7.21 & .048 \\
\hline \multicolumn{5}{|l|}{ IL-1 $\beta$} \\
\hline Aneurysmal expression (mean $\pm S D$, arbitrary units) & $2.12 \pm 0.36 \times 10^{-2}$ & & $5.92 \pm 0.90 \times 10^{-3}$ & \\
\hline Normal expression (mean $\pm S D$, arbitrary units) & $5.86 \pm 0.73 \times 10^{-3}$ & & $1.54 \pm 0.50 \times 10^{-2}$ & \\
\hline RT-qPCR aneurysmal/normal ratio & 3.61 & $<.001$ & 0.38 & $>.05$ \\
\hline Microarray aneurysmal/normal ratio & 5.41 & .040 & 1.01 & $>.05$ \\
\hline \multicolumn{5}{|l|}{ TNF- $\alpha$} \\
\hline Aneurysmal expression (mean $\pm \mathrm{SD}$, arbitrary units) & $3.51 \pm 1.36 \times 10^{-3}$ & & $1.47 \pm 0.31 \times 10^{-4}$ & \\
\hline Normal expression (mean $\pm S D$, arbitrary units) & $2.31 \pm 1.50 \times 10^{-4}$ & & $5.86 \pm 2.30 \times 10^{-5}$ & \\
\hline RT-qPCR aneurysmal/normal ratio & 15.24 & .024 & 2.50 & $>.05$ \\
\hline Microarray aneurysmal/normal ratio & 26.63 & .047 & 3.16 & $>.05$ \\
\hline \multicolumn{5}{|l|}{ Vascular cellular adhesion molecule 1} \\
\hline Aneurysmal expression (mean $\pm S D$, arbitrary units) & $1.29 \pm 0.10 \times 10^{0}$ & & $2.65 \pm 0.88 \times 10^{-1}$ & \\
\hline Normal expression (mean $\pm S D$, arbitrary units) & $5.57 \pm 0.76 \times 10^{-1}$ & & $6.27 \pm 1.32 \times 10^{-1}$ & \\
\hline RT-qPCR aneurysmal/normal ratio & 2.31 & $<.001$ & 0.42 & $>.05$ \\
\hline Microarray aneurysmal/normal ratio & 7.81 & .001 & 1.94 & $>.05$ \\
\hline \multicolumn{5}{|l|}{ Cathepsin D } \\
\hline Aneurysmal expression (mean $\pm \mathrm{SD}$, arbitrary units) & $4.51 \pm 1.28 \times 10^{-1}$ & & $1.52 \pm 0.94 \times 10^{-1}$ & \\
\hline Normal expression (mean $\pm S D$, arbitrary units) & $1.60 \pm 0.56 \times 10^{-1}$ & & $3.53 \pm 2.94 \times 10^{-2}$ & \\
\hline RT-qPCR aneurysmal/normal ratio & 2.82 & .045 & 4.29 & $>.05$ \\
\hline Microarray aneurysmal/normal ratio & 4.96 & .002 & 1.34 & $>.05$ \\
\hline
\end{tabular}

aneurysmal disease (expansion and rupture) than those that might exist during early stages of aneurysm formation, it is also clear that the transcriptional alterations identified in this study will need to be confirmed at the protein level, proceeding thereafter to functional assessment of their relevance in in vivo model systems. Nonetheless, with these limitations in mind, the expression profiles derived from this study provide a valuable start toward evaluating gene expression patterns that characterize established aneurysmal disease in the thoracic and abdominal aorta and, perhaps of equal importance, determining how such patterns differ between TAAs and AAAs.

Not surprisingly, many of the genes altered in TAAs and AAAs are involved in intracellular signal transduction and transcriptional activation pathways. The differences between TAAs and AAAs may therefore reflect either the presence or absence of different cell types or the dominance of different cellular activation and signaling pathways in each disease. For example, two particular isoforms of PKC were expressed at relatively high levels in TAAs versus 
NTA, PKC- $\zeta$ and PKC- $\theta$ ( $>100$-fold and 14-fold, respectively), whereas AAAs were associated with a 7-fold increase in expression of PKC- $\delta$ but no significant alterations in other PKC isoforms. Although regulation of PKC activity occurs largely through phosphorylation events by upstream mediators of cell activation, the dominant presence of certain isoforms may influence downstream events by determining how cells respond to PKC activation. ${ }^{37,38}$

With respect to other functionally-related groups of genes, Table 1 reveals that TAAs were associated with pronounced increases in the expression of genes involved in regulating cell survival, proliferation, and programmed cell death, including the DNA repair enzyme uracil-DNA glycosylase (44-fold), ${ }^{39}$ lymphotoxins $\alpha$ (8-fold) and $\beta$ (41fold), ${ }^{40}$ TNF- $\alpha$ (27-fold), CD27 (a TNF receptor superfamily member, 18 -fold), ${ }^{41}$ platelet-derived growth factor receptor $\alpha$ (11-fold), early growth response 1 (10-fold), ${ }^{42}$, cyclins D2 (5-fold) and D3 (4-fold), jun D (7-fold), IL-1 $\beta$ (5-fold), and the IL-1 $\beta$ converting enzyme homolog ICELAP3 (6-fold). ${ }^{43}$ If verified at the protein level, the increased local production of soluble cytotoxic mediators, such as TNF- $\alpha$ and IL- $1 \beta$, may be particularly relevant to the medial SMC dysfunction and depletion observed in TAAs. Indeed, several reports have suggested that programmed cell death may play a role in the medial degeneration observed in TAAs ${ }^{24}$ and it is recognized that both TNF- $\alpha$ and IL- $1 \beta$ are potent inducers of apoptosis and nitric oxide production in cultured vascular SMCs, particularly when acting in combination. ${ }^{44,45}$

Table 2 demonstrates that AAAs were associated with increased expression of a number of genes related to atherosclerosis and chronic inflammation that were not increased in TAAs, such as those encoding the T-cell costimulatory molecule $\mathrm{CD} 86 / \mathrm{B} 7-2$ antigen (43-fold), ${ }^{46}$ apoplipoprotein E (15-fold), IL-8 (7-fold), GATA-3 (7fold) ${ }^{47}$ nuclear factor of activated $\mathrm{T}$ cells (6-fold), ${ }^{48,49}$ myeloid cell nuclear differentiating antigen (5-fold), macrophage stimulating 1 (4-fold), nuclear factor $\kappa \mathrm{B}$ p105 (4-fold), inducible nitric oxide synthase (nitric oxide synthase II, 3-fold), urinary-type plasminogen activator receptor (4-fold), and thrombin receptor (4-fold). Genes encoding a number of cell adhesion molecules were also selectively increased in AAAs, such as integrins $\beta_{2}$ (13-fold), $\beta_{8}$ (8fold), $\alpha_{4}$ (6-fold), and $\alpha_{\mathrm{L}}$ (4-fold), as well as selectin $\mathrm{E}$ (6-fold). Furthermore, it is notable that AAAs were associated with significantly decreased expression of growth arrest and DNA damage inducible 45 (9-fold decrease), ${ }^{50}$ smooth muscle and nonmuscle myosin light chain kinase (20-fold decrease), and transforming growth factor $\beta$ receptor type I (50-fold decrease), which may all reflect the pronounced SMC depletion in AAAs.

Perhaps the most important alteration common to both TAAs and AAAs was the marked increase in expression of
MMP-9/gelatinase B (9-fold in TAAs vs NTA and 86-fold in AAAs vs NAA), an observation consistent with previous studies demonstrating that production of MMP-9 is increased in TAAs and dissections and in AAAs.${ }^{51-53}$ MMP-9 is thought to contribute to elastin degradation in aneurysmal disease, because it exhibits enzymatic activity against elastic fibers and other extracellular matrix proteins and because it is produced by medial SMC and aneurysm-infiltrating macrophages. ${ }^{52,53}$ It has also been shown that MMP-9 is overexpressed in various experimental animal models of AAAs, that MMP inhibitors suppress development of experimental AAAs in rats and mice, and that mice lacking MMP-9 are resistant to aneurysm development. ${ }^{35,54-57}$ In the context of these observations, it appears likely that increased expression of MMP-9 plays a central role in the destructive remodeling of the elastic media associated with aortic aneurysms, regardless of their location or initiating etiology.

Although the clinical significance of this work is yet unknown, the altered patterns of gene expression identified here will provide a valuable foundation for further investigations into the pathobiology of aortic aneurysmal disease. This study also demonstrates that significant heterogeneity exists between TAAs and AAAs at the molecular level and illustrates the use of high-throughput cDNA microarrays to generate novel information. Further applications of gene expression profiling can be expected to substantially enhance our understanding of the diverse processes involved in aneurysmal degeneration.

We thank Dr John A. Curci and Sarah J. VanVickle-Chavez for technical assistance and Drs J. Perren Cobb and Richard B. Schuessler for helpful discussions.

\section{References}

1. Roberts CS, Roberts WC. Dissection of the aorta associated with congenital malformation of the aortic valve. J Am Coll Cardiol. 1991;17:712-6.

2. Ando M, Okita Y, Morota T, Takamoto S. Thoracic aortic aneurysm associated with congenital bicuspid aortic valve. Cardiovasc Surg. 1998;6:629-34.

3. Sundt TM, Mora BN, Moon MR, Bailey MS, Pasque MK, Gay WA. Options for repair of a bicuspid aortic valve and ascending aortic aneurysm. Ann Thorac Surg. 2000;69:1333-7.

4. Pepin M, Schwarze U, Superti-Furga A, Byers PH. Clinical and genetic features of Ehlers-Danlos syndrome type IV, the vascular type. N Engl J Med. 2000;342:673-80.

5. Dietz HC. Molecular etiology, pathogenesis and diagnosis of the Marfan syndrome. Prog Pediatr Cardiol. 1996;5:159-66.

6. Milewicz DM, Michael K, Fisher N, Coselli JS, Markello T, Biddinger A. Fibrillin-1 (Fbn1) mutations in patients with thoracic aortic aneurysms. Circulation. 1996;94:2708-11.

7. Furthmayr H, Francke U. Ascending aortic aneurysm with or without features of Marfan syndrome and other fibrillinopathies: new insights. Semin Thorac Cardiovasc Surg. 1997;9:191-205.

8. Vaughan CJ, Casey M, He J, Veugelers M, Henderson K, Guo D, et al. Identification of a chromosome 11q23.2-q24 locus for familial aortic aneurysm disease, a genetically heterogeneous disorder. Circulation. 2001;103:2469-75.

9. Guo D, Hasham S, Kuang SQ, Vaughan CJ, Boerwinkle E, Chen H, et 
al. Familial thoracic aortic aneurysms and dissections: genetic heterogeneity with a major locus mapping to 5q13-14. Circulation. 2001; 103:2461-8.

10. Erdheim J. Medionecrosis aortae idiopathica cystica. Virchows Arch Path Anat. 1930;276:187.

11. Niwa K, Perloff JK, Bhuta SM, Laks H, Drinkwater DC, Child JS, et al. Structural abnormalities of great arterial walls in congenital heart disease: light and electron microscopic analyses. Circulation. 2001; 103:393-400.

12. Thompson RW, Lee JK, Curci JA. The pathobiology of abdominal aortic aneurysms. In: Gewertz BL, editor. Surgery of the aorta and its branches. Philadelphia: WB Saunders; 2000. p. 75-106.

13. Keen RR, Dobrin PB. Development of aneurysms. Georgetown (TX): Landes Bioscience; 2000.

14. Coady MA, Rizzo JA, Goldstein LJ, Elefteriades JA. Natural history, pathogenesis, and etiology of thoracic aortic aneurysms and dissections. Cardiol Clin. 1999;14:615-35.

15. Tamarina NA, McMillan WD, Shively VP, Pearce WH. Expression of matrix metalloproteinases and their inhibitors in aneurysms and normal aorta. Surgery. 1997;122:264-71.

16. Elmore JR, Keister BF, Franklin DP, Youkey JR, Carey DJ. Expression of matrix metalloproteinases and TIMPs in human abdominal aortic aneurysms. Ann Vasc Surg. 1998;12:221-8.

17. Sukhova GK, Shi GP, Simon DI, Chapman HA, Libby P. Expression of the elastolytic cathepsins $\mathrm{S}$ and $\mathrm{K}$ in human atheroma and regulation of their production in smooth muscle cells. J Clin Invest. 1998;102: 576-83.

18. Shi GP, Sukhova GK, Grubb A, Ducharme A, Rhode LH, Lee RT, et al. Cystatin $\mathrm{C}$ deficiency in human atherosclerosis and aortic aneurysms. J Clin Invest. 1999;104:1191-7.

19. Koch A, Kunkel S, Pearce W, Shah M, Parikh D, Evanoff H, et al. Enhanced production of the chemotactic cytokines interleukin-8 and monocyte chemoattractant protein-1 in human abdominal aortic aneurysms. Am J Pathol. 1993;142:1423-31.

20. Lopez-Candales A, Holmes DR, Liao S, Scott MJ, Wickline SA, Thompson RW. Decreased vascular smooth muscle cell density in medial degeneration of human abdominal aortic aneurysms. Am J Pathol. 1997;150:993-1007.

21. Henderson EL, Gang YJ, Sukhova GK, Whittemore AD, Knox J, Libby P. Death of smooth muscle cells and expression of mediators of apoptosis by $\mathrm{T}$ lymphocytes in human abdominal aortic aneurysms. Circulation. 1999;99:96-104.

22. Marsalese DL, Moodie DS, Lytle BW, Cosgrove DM, Ratliff NB, Goormastic M, et al. Cystic medial necrosis of the aorta in patients without Marfan's syndrome: surgical outcome and long-term followup. J Am Coll Cardiol. 1990;16:68-73.

23. de Sa M, Moshkovitz Y, Butany J, David TE. Histologic abnormalities of the ascending aorta and pulmonary trunk in patients with bicuspid aortic valve disease: clinical relevance to the Ross procedure. $J$ Thorac Cardiovasc Surg. 1999;118:588-94.

24. Bonderman D, Gharehbaghi-Schnell E, Wollenek G, Maurer G, Baumgartner H, Lang IM. Mechanisms underlying aortic dilatation in congenital aortic valve malformation. Circulation. 1999;99:2138-43.

25. Lesauskaite V, Tanganelli P, Sassi C, Neri E, Diciolla F, Ivanoviene L, et al. Smooth muscle cells of the media in the dilatative pathology of ascending thoracic aorta: morphology, immunoreactivity for osteopontin, matrix metalloproteinases, and their inhibitors. Hum Pathol. 2001; 32:1003-11

26. Segura AM, Luna RE, Horiba K, Stetler-Stevenson WG, McAllister HA, Willerson JT, et al. Immunohistochemistry of matrix metalloproteinases and their inhibitors in thoracic aortic aneurysms and aortic valves of patients with Marfan's syndrome. Circulation. 1998;98(19 Suppl):II331-7.

27. Heller RA, Schena M, Chai A, Shalon D, Bedilion T, Gilmore J, et al. Discovery and analysis of inflammatory disease-related genes using cDNA microarrays. Proc Natl Acad Sci U S A. 1997;94:2150-5.

28. Schena M, Heller RA, Theriault TP, Konrad K, Lachenmeier E, Davis RW. Microarrays: biotechnology's discovery platform for functional genomics. Trends Biotechnol. 1998;16:301-6.

29. Eisen MB, Spellman PT, Brown PO, Botstein D. Cluster analysis and display of genome-wide expression patterns. Proc Natl Acad Sci U S A. 1998;95:14863-8.

30. Iyer VR, Eisen MB, Ross DT, Schuler G, Moore T, Lee JC, et al. The transcriptional program in the response of human fibroblasts to serum. Science. 1999;283:83-7.

31. Lockhart DJ, Winzeler EA. Genomics, gene expression and DNA arrays. Nature. 2000;405:827-36.

32. Haley KJ, Lilly CM, Yang JH, Feng Y, Kennedy SP, Turi TG, Thompson JF, et al. Overexpression of eotaxin and the CCR3 receptor in human atherosclerosis: using genomic technology to identify a potential novel pathway of vascular inflammation. Circulation. 2000; 102:2185-9.

33. Tung WS, Lee JK, Thompson RW. Simultaneous analysis of 1176 gene products in normal human aorta and abdominal aortic aneurysms using a membrane-based complementary DNA expression array. $J$ Vasc Surg. 2001;34:143-50.

34. Armstrong PJ, Johanning JM, Calton WC Jr, Delatore JR, Franklin DP, Han DC, et al. Differential gene expression in human abdominal aorta: aneurysmal versus occlusive disease. J Vasc Surg. 2002;35:34655.

35. Pyo R, Lee JK, Shipley JM, Curci JA, Mao D, Ziporin SJ, et al. Targeted gene disruption of matrix metalloproteinase-9 (gelatinase B) suppresses development of experimental abdominal aortic aneurysms. $J$ Clin Invest. 2000;105:1641-9.

36. Lee JK, Borhani M, Ennis TL, Upchurch GR, Thompson RW. Experimental abdominal aortic aneurysms in mice lacking expression of inducible nitric oxide synthase. Arterioscler Thromb Vasc Biol. 2001; 21:1393-401.

37. Kochs G, Hummel R, Meyer D, Hug H, Marme D, Sarre TF. Activation and substrate specificity of the human protein kinase $\mathrm{C}$ alpha and zeta isoenzymes. Eur J Biochem. 1993;216:597-606.

38. Baier G, Telford D, Giampa L, Coggeshall KM, Baier-Bitterlich G, Isakov N, et al. Molecular cloning and characterization of PKC theta, a novel member of the protein kinase $\mathrm{C}$ (PKC) gene family expressed predominantly in hematopoietic cells. J Biol Chem. 1993;268:49975004.

39. Olsen LC, Aasland R, Wittwer CU, Krokan HE, Helland DE. Molecular cloning of human uracil-DNA glycosylase, a highly conserved DNA repair enzyme. EMBO J. 1989;8:3121-5.

40. Browning JL, Ngam-ek A, Lawton P, DeMarinis J, Tizard R, Chow EP, et al. Lymphotoxin beta, a novel member of the TNF family that forms a heteromeric complex with lymphotoxin on the cell surface. Cell. 1993;72:847-56.

41. Camerini D, Walz G, Loenen WA, Borst J, Seed B. The T cell activation antigen CD27 is a member of the nerve growth factor/tumor necrosis factor receptor gene family. J Immunol. 1991;147:3165-9.

42. Lowe HC, Fahmy RG, Kavurma MM, Baker A, Chesterman CN, Khachigian LM. Catalytic oligodeoxynucleotides define a key regulatory role for early growth response factor- 1 in the porcine model of coronary in-stent restenosis. Circ Res. 2001;89:670-7.

43. Duan H, Chinnaiyan AM, Hudson PL, Wing JP, He WW, Dixit VM. ICE-LAP3, a novel mammalian homologue of the Caenorhabditis elegans cell death protein Ced-3, is activated during Fas- and tumor necrosis factor-induced apoptosis. J Biol Chem. 1996;271:1621-5.

44. Beasley D, Eldridge M. Interleukin-1 beta and tumor necrosis factoralpha synergistically induce NO synthase in rat vascular smooth muscle cells. Am J Physiol. 1994;266(4 Pt 2):R1197-203.

45. Geng YJ, Wu Q, Muszynski M, Hansson GK, Libby P. Apoptosis of vascular smooth muscle cells induced by in vitro stimulation with interferon-gamma, tumor necrosis factor-alpha, and interleukin-1 beta. Arterioscler Thromb Vasc Biol. 1996;16:19-27.

46. Freeman GJ, Gribben JG, Boussiotis VA, Ng JW, Restivo VA, Lombard LA, et al. Cloning of B7-2: a CTLA-4 counter-receptor that costimulates human T cell proliferation. Science. 1993;262:909-11.

47. Kishikawa H, Sun J, Choi A, Miaw SC, Ho IC. The cell type-specific expression of the murine IL-13 gene is regulated by GATA-3. J Immunol. 2001;167:4414-20.

48. Horsley V, Pavlath GK. NFAT: ubiquitous regulator of cell differentiation and adaptation. $J$ Cell Biol. 2002;156:771-4

49. Graef IA, Chen F, Chen L, Kuo A, Crabtree GR. Signals transduced by 
$\mathrm{Ca}(2+) /$ calcineurin and NFATc3/c4 pattern the developing vasculature. Cell. 2001;105:863-75.

50. Kettenhofen R, Hoppe J, Eberhard G, Seul C, Ko Y, Sachinidis A. Regulation of Gadd45a mRNA expression in vascular smooth muscle under growth and stress conditions. Cell Signal. 2001;13:787-99.

51. Schneiderman J, Bordin GM, Adar R, Smolinsky A, Seiffert D, Engelberg I, et al. Patterns of expression of fibrinolytic genes and matrix metalloproteinase-9 in dissecting aortic aneurysms. Am J Pathol. 1998; 152:703-10.

52. Thompson RW, Holmes DR, Mertens RA, Liao S, Botney MD, Mecham RP, et al. Production and localization of 92-kilodalton gelatinase in abdominal aortic aneurysms: an elastolytic metalloproteinase expressed by aneurysm-infiltrating macrophages. J Clin Invest. 1995; 96:318-26.

53. McMillan WD, Patterson BK, Keen RR, Shively VP, Cipollone M, Pearce WH. In situ localization and quantification of mRNA for 92-kD type IV collagenase and its inhibitor in aneurysmal, occlusive, and normal aorta. Arterioscler Thromb Vasc Biol. 1995;15:1139-44.

54. Halpern VJ, Nackman GB, Gandhi RH, Irizarry E, Scholes JV, Ramey WG, et al. The elastase infusion model of experimental aortic aneurysms: synchrony of induction of endogenous proteinases with matrix destruction and inflammatory cell response. J Vasc Surg. 1994;20:5160.

55. Petrinec D, Liao S, Holmes DR, Reilly JM, Parks WC, Thompson RW. Doxycycline inhibition of aneurysmal degeneration in an elastaseinduced rat model of abdominal aortic aneurysm: preservation of aortic elastin associated with suppressed production of $92 \mathrm{kD}$ gelatinase. $J$ Vasc Surg. 1996;23:336-46.

56. Longo GM, Xiong W, Greiner TC, Zhao Y, Fiotti N, Baxter BT Matrix metalloproteinases 2 and 9 work in concert to produce aortic aneurysms. J Clin Invest. 2002;110:625-32.

57. Bunton TE, Biery NJ, Myers L, Gayraud B, Ramirez F, Dietz HC Phenotypic alteration of vascular smooth muscle cells precedes elastolysis in a mouse model of Marfan syndrome. Circ Res. 2001;88:3743.

\section{Discussion}

Dr Frank W. Sellke (Boston, Mass). Can you comment on how you performed the biopsies to make sure that there was consistency between the TAA and AAA specimens? Because there is so much, how do I put it, grungy material in aneurysms of both types, especially AAAs, how did you take this into consideration? Also, can you comment on the statistical analysis specific for cDNA array technology?

Dr Absi. Thank you, Dr Sellke. With respect to the biopsies, I obtained TAA specimens from the attending surgeons who were performing the procedure, basically as a ring of tissue removed when they had completed aneurysm repair. This tissue was snapfrozen immediately in liquid nitrogen, and at a later time I extracted the messenger RNA. AAA repair was basically performed by endoaneurysmorrhaphy, so in these cases I obtained a slice of tissue along the whole length of aneurysm itself.

With respect to the statistical analysis, it is true that we did not have a high number of blots. In going over the statistical analysis, especially that provided with the software, our approach was in agreement with literature reports indicating that with 5 blots one can achieve reproducible results. Just because you are dealing with 1185 genes, the parametric analysis must be done with some adjustments in a special kind of analysis of variance, such as the
Kruskal-Wallis test, which can be of help when you have a relatively small number of samples.

Dr Michael J. Reardon (Houston, Tex). Congratulations on a nice study and a nice presentation. I did have one question about your normal samples. Were they from donors, or were they from the recipients in transplants? Because if they came from donors, they clearly came from much younger people, and there may be altered gene expression with age. We have started taking some plugs from the ascending aorta from coronaries to use those as normal specimens. Would you comment on your normal specimens?

Dr Absi. Thank you, Dr Reardon. I am glad that you brought that up. That is an important issue, and we did not mean to minimize it during the presentation. The pathophysiology of aneurysmal disease is thought to include numerous factors, age and atherosclerosis among them. We chose to use donors for our normal controls, who were young, because we did not want to bias against any of these factors, namely age, in that situation. Age may make a difference and at least some of the results we obtained may be due to age. For this reason we are also planning in the future to compare results in aneurysms with age-matched samples obtained from patients undergoing coronary artery bypass grafting. However, if we had selected or stratified for age in this initial study we would have tended to bias against it, and we did not want to do that here.

Dr Anthony L. Estrera (Houston, Tex). This was a nice study. My question is in relation to gender predominance. In our experience in Houston, our patients with thoracoabdominal and ascending arch repairs are primarily male, with a ratio of about $3: 2$; whereas in our infrarenal replacements there is a greater male predominance, about a 10:1 ratio. Do you have a comment? I appreciate the small numbers in your study, but that would be something to look at in the future.

Dr Absi. We simply chose our patients randomly over a certain period of time during the conduct of the study, without selection for gender, and agree that this will be an important issue to examine in the future.

Dr Larry R. Kaiser (Philadelphia, $\mathrm{Pa}$ ). You mentioned that apolipoprotein E was 14-fold upregulated in, I think, the AAAs. Are you concerned that the high concentration of apolipoprotein $\mathrm{E}$ was due to contamination, perhaps by infiltrating foam cells in the arterial wall, and did you use laser capture microdissection to remove some of these foam cells and infiltrating leukocytes that might have interfered?

Dr Absi. No, we did not use that technique, as this study was not designed to identify the cell types or locations where the changes in gene expression occurred, but only to provide a broad survey of changes in gene expression within the tissue samples as a whole. There are clearly a variety of different cell types present within aneurysm tissues, including macrophages and vascular smooth muscle cells, but the cells in which the changes in gene expression were occurring were not examined in this initial investigation. This is another promising approach for the future. 